Disponível em:

http://editora.unoesc.edu.br/index.php/race

Race, Joaçaba, v. 15, n. 2, p. 649-684, maio/ago. 2016

\title{
PRODUÇÃO ACADÊMICA DAS TEORIAS ENFATIZADAS NOS ESTUDOS DIVULGADOS NOS PERIÓDICOS NACIONAIS
}

Academic production of theories emphasized in studies reported in national journals

Henrique César Melo Ribeiro

E-mail: hcmribeiro@hotmail.com

Doutor em Administração de Empresas pela Universidade Nove de Julho; Mestre em

Administração de Empresas pela Universidade de Fortaleza; Professor Adjunto do curso de Administração da Universidade Federal do Piauí de Ministro Reis Velloso. Endereço para contato: Avenida São Sebastião, 2819, São Benedito, 64202-020, Parnaíba, Piauí, Brasil.

Marianne Corrêa dos Santos

E-mail: mariannecorrea@hotmail.com

Especialista em Docênciado Ensino Superior pela Faculdade Piauiense; mestranda em Administração de Empresas pela Universidade Estadual do Ceará; Professora do Curso de Administração da Faculdade Maurício de Nassau de Parnaíba.

Artigo recebido em 13 de maio de 2015. Aceito em 30 de março de 2016. 


\section{Resumo}

O objetivo com este estudo foi investigar a produção acadêmica de Teorias colocadas em evidência nos estudos divulgados nos periódicos nacionais da área de Administração, Contabilidade e Turismo no período de 1999 a 2013. Metodologicamente, utilizaram-se as técnicas de análise bibliométrica e de rede social, visto que esta última focou a análise two-mode. Os principais achados foram: evolução de estudos que colocaram em destaque Teorias a partir de 1999, alcançando seu ápice em 2013. O periódico Cadernos EBAPE.BR ficou em destaque neste trabalho. A Teoria Institucional ficou em evidência em 32 estudos publicados; o tema mais publicado nesta pesquisa foi estratégia organizacional, com 33 manuscritos publicados. Em relação à análise de rede social two-mode, as Teorias Institucional e a das Restrições ficaram em realce; e o tema estratégia organizacional apareceu com maior ênfase. Conclui-se, de maneira geral, um perfil macro das Teorias que foram colocadas em proeminência nos 364 artigos investigados, contribuindo para entender e compreender quais Teorias se encontram legitimadas na literatura acadêmica nacional, cooperando para a difusão e a socialização do conhecimento científico, mediante a divulgação de temas maduros e/ou emergentes na área de Administração, Contabilidade e Turismo, colaborando, assim, para uma maior densidade e robustez desse campo do saber.

Palavras-chave: Teorias. Produção acadêmica. Periódicos nacionais. Pesquisa bibliométrica.

Abstract

The objective with this study was to investigate the academic production of the Theories put in evidence in the studies published in national journals of Administration, Accounting and Tourism area from 1999 to 2013. In terms of methodology, we used the techniques of bibliometric analysis and social networking, and the latter focused on the two-mode analysis. The main findings were: evolution studies that put highlighted Theories from 1999, reaching its peak in 2013. The journal Cadernos EBAPE.BR, was highlighted in this work. Institutional Theory was in evidence in 32 published studies, the theme more research was published on organizational strategy, with 33 published manuscripts. Regarding the two-mode social network analysis, Institutional Theory of Constraints and were in enhancement; and the subject organizational strategy appeared with greater emphasis. It follows in general, one of the Theories macro profile which have been prominent in the 364 investigated articles, contributing to understand and comprehend what Theories are legitimized in the national academic literature, cooperating for the dissemination and socialization of scientific knowledge, by disseminating of mature and/or emerging issues in the field of Administration, Accounting and Tourism area, thus contributing to a higher density and robustness of this field of knowledge.

Keywords: Theories. Academic production. National journals. Bibliometric research. 


\section{INTRODUÇÃO}

A realização de mapeamentos sobre a produção acadêmica de determinado campo do conhecimento e/ou tema científico é extremamente usual em termos globais, pois esses estudos ocupam lugar de destaque, sendo publicados em diversos periódicos internacionais e nacionais (JABBOUR; SANTOS; BARBIERI, 2008).

Por meio dessa análise longitudinal, é possível mensurar várias características de um tema e/ou área do conhecimento científico (WALTER; BACH, 2013), como, por exemplo, a produção científica de Teorias (AMBONI; CAMINHA; ANDRADE, 2012; ROCHA et al., 2012) na área de Administração, Contabilidade e Turismo. E os periódicos, sobretudo dessa área, são fontes fundamentais para se aferir o impacto da produção científica dessas Teorias na literatura acadêmica (BEUREN; SOUZA, 2008).

Diante do exposto, foi pesquisado e observado que na literatura acadêmica nacional, foram publicados diversos estudos que versaram sobre a produção acadêmica de Teorias distintas as quais fornecem embasamento teórico a diferentes temas da área de Administração, Contabilidade e Turismo, os quais são evidenciados a seguir.

Barbosa Neto e Colauto (2010) identificaram a produção científica na área de Contabilidade que continha a abordagem da Teoria Institucional como plataforma teórica. Os autores constataram que apesar de os estudos sobre a referida Teoria serem embrionários no Brasil, o volume de estudos vem crescendo ao longo dos últimos anos. Cruz et al. (2010) analisaram os trabalhos científicos com abordagem no tema Teoria das Restrições, apresentados no Congresso Brasileiro de Custos (CBC) de 1994 a 2008. Os autores observaram a concentração dos livros nas referências dos artigos publicados no referido Congresso.

Gubiani e Lavarda (2011) mapearam as publicações sobre finanças comportamentais e Teoria do Prospecto nos Anais do Congresso da Universidade de São Paulo, da Associação Nacional dos Programas de Pós-graduação em Ciências Contábeis (Anpcont), do Enanpad e dos Seminários em Administração (Semead) de 2000 a 2009. Concluíram que as revistas internacionais, os livros internacionais e os anais de congressos nacionais foram as referências mais citadas na produção dos artigos analisados. Percebe-se, assim, uma utilização maior de referências internacionais sobre o acenado tema.

Amboni, Caminha e Andrade (2012) verificaram a compatibilidade do padrão teórico descrito pela Lei de Lotka, com a distribuição da produtividade de autores acerca da Teoria Neoinstitucional, em periódicos e nos Anais do Enanpad, no período 
de 1990 a 2010. Contemplaram que os temas estudos organizacionais, estratégia organizacional e gestão pública foram os principais relacionados à produção em Teoria Neoinstitucional. Pereira (2012) mapeou os estudos sobre a Teoria Institucional. O pesquisador verificou que a mencionada Teoria é estudada no âmbito teórico e prático, e, presentemente, é empregada em vários contextos organizacionais, comprovando que as organizações sentem a obrigação de padronizar comportamentos e alastrar a identidade organizacional entre os stakeholders.

Rocha et al. (2012) analisaram a produção acadêmica da Teoria da Agência e da Assimetria da Informação na Contabilidade em âmbito nacional e internacional. Concluíram que a citada Teoria é mais pesquisada no panorama internacional. Arruda et al. (2013) analisaram o desenvolvimento da Teoria dos Custos de Transação (TCT) nos Encontros da Associação Nacional de Pós-graduação e Pesquisa em Administração (Enanpad) de 1997 a 2010. Os articulistas constataram o potencial de alargamento de estudos com foco na TCT em todas as áreas dos Enanpads.

Colauto e Almeida (2013) analisaram a produção científica publicada por congressos e periódicos que contenham a abordagem da Teoria Institucional em suas respectivas plataformas teóricas entre os anos 2009 e 2012. Os pesquisadores constataram que há uma crescente relevância desses estudos na academia, mas ainda não suficiente para o desenvolvimento dessa Teoria no ambiente nacional. Ferreira, Pinto e Serra (2013) examinaram se a Teoria dos Custos de Transação tem impacto nas pesquisas sobre negócios internacionais de 1982 a 2010, em uma amostra de 377 artigos. Os autores observaram uma forte influência da citada Teoria sobre os estudos dos negócios internacionais nas últimas três décadas.

Souza et al. (2013) analisaram o perfil da produção científica sobre a Teoria dos Ajustamentos Contábeis do Lucro nos periódicos de contabilidade com estrato Capes no triênio 2010-2012. O periódico Contabilidade Vista \& Revista se destacou na produção da aludida Teoria. Silva e Zuccolotto (2014) avaliam a produção científica na área de Teoria da Contabilidade, publicada na Revista de Contabilidade e Finanças (RCF) da USP, de 2001 a 2010. Nesta foi observado o crescimento das publicações sobre a mencionada Teoria, conseguindo seu ápice em 2005.

Os estudos evidenciados nos parágrafos anteriores mostram que a produção científica sobre diferentes teorias ainda é recente, contudo, está em evolução. Observando-se tais trabalhos não se contatou nenhum em que se vislumbra a investigação da produção acadêmica de Teorias colocadas em evidência nos estudos divulgados nos periódicos nacionais da área de Administração, Contabilidade e Turismo no período de 1999 a 2013. Assim, foi o objetivo principal deste estudo, norteado pela seguin- 
te questão de pesquisa: qual o perfil e a produção acadêmica de Teorias colocadas em evidência nos estudos divulgados nos periódicos nacionais da área de Administração, Contabilidade e Turismo no período de 1999 a 2013?

Pesquisas com esse foco, e por serem longitudinais, costumam ser orientadas e embasadas pelas técnicas de análise bibliométrica e de rede social (RIBEIRO; COSTA; FERREIRA, 2014), visto que esta última, neste estudo, colocará em destaque a técnica de rede two-mode (RIBEIRO, 2013a), oferecendo a possibilidade de um melhor entendimento de todas as nuances que englobam os estudos científicos direcionados a determinado campo do conhecimento e/ou tema acadêmico, contribuindo para a sua compreensão e gerando a possibilidade de criação de grupos de estudos, novas pesquisas, novos meios de comunicação, cooperando para o seu desenvolvimento teórico na literatura acadêmica nacional e, também, internacional.

Justifica-se fazer este trabalho em razão de não ter sido possível encontrar estudos similares, na literatura acadêmica nacional e internacional, ao que nesta pesquisa se propõe a responder e a fazer. Outra justificativa para se realizar esta investigação é a possibilidade de um mapeamento de diferentes Teorias vinculadas aos periódicos da área de Administração, Contabilidade e Turismo, contribuindo para demonstrar dados e informações, mediante indicadores bibliométricos e sociométricos, de como estão sendo publicados os papers que colocam em evidência diversas Teorias relacionadas a esse campo do conhecimento, abordando, também, seus respectivos temas que se alinham a elas. E, por fim, esta pesquisa explora 60 revistas com extrato de B2 a A2, considerando-se o triênio 2010-2012, ou seja, o triênio mais atual da Capes, contemplando atualizadas as notas dos 60 periódicos investigados neste trabalho, contribuindo para a geração de dados e informações atuais sobre o tema a ser analisado.

\section{FUNDAMENTAÇÃO TEÓRICA}

Esta seção contempla conceitos e realces sobre a bibliometria e as redes sociais. Evidencia, também, a importância que as Teorias têm para o alicerce teórico dos estudos científicos e, consequentemente, para a propagação do conhecimento.

\subsection{BIBLIOMETRIA E REDES SOCIAIS}

A análise bibliométrica é uma metodologia empregada para avaliar a tipologia, a quantidade e a qualidade das fontes de informação citadas em estudos acadêmicos; o produto dessa análise bibliométrica são os indicadores científicos por ela 
aferidos (SILVA; HAYASHI; HAYASHI, 2011); estes devem ser consistentes e padronizados (SARTORI et al., 2014). Realça-se que para este estudo esses indicadores mensuraram a produção acadêmica das Teorias colocadas em ênfase na área de Administração, Contabilidade e Turismo.

Para fornecer embasamento e sustentação à análise bibliométrica, surgem as Leis da bibliometria: Lei de Lotka, Lei de Bradford e Lei de Zipf, que têm sido utilizadas em várias pesquisas científicas, como nos estudos de Cardoso et al. (2005), Beuren e Souza (2008), Moretti e Campanario (2009), Gomes e Scarpin (2012), Ribeiro et al. (2012), Vitorino Filho et al. (2012), Peleias et al. (2013) e Souza e Ribeiro (2013).

A Lei de Lotka ou Lei do Quadrado Inverso foca na aferição da produtividade dos autores por meio de um modelo de classificação de tamanho-frequência dos diversos acadêmicos em um conjunto de textos (CARDOSO et al., 2005). A fórmula matemática que apresenta a citada Lei pode ser descrita como o número de pesquisadores que publica n artigos (LEITE FILHO, 2008):

$$
\alpha_{n}=\alpha_{1} \cdot \frac{1}{n^{2}}
$$

Em que $\alpha \mathrm{n}=$ número de pesquisadores que publicaram n papers, $\alpha 1$ = número de acadêmicos que publicaram um manuscrito e $\mathrm{n}=$ número total de artigos (LEITE FILHO, 2008).

Em relação à Lei de Bradford ou Lei de Dispersão, calcula-se o grau de importância de periódicos em determinada área do conhecimento, isto é, as revistas que publicam o maior número de papers sobre determinado tema formam um núcleo de revistas, com suposição de maior qualidade ou realce para aquela área (BEUREN; SOUZA, 2008).

Verifica-se, assim, que os artigos iniciais de um determinado tema são submetidos a um número limitado de revistas. A concordância e divulgação desses manuscritos estimulam outros acadêmicos optantes desse tema a conduzirem seus papers para esses periódicos. Concomitantemente, outras revistas notam a evolução da temática e iniciam a divulgação de artigos sobre ela. Com o crescimento do interesse sobre o tema e seu respectivo aperfeiçoamento, torna-se possível a afirmação de um núcleo de revistas que mais publicaram em determinada área do conhecimento (MACHADO JÚNIOR et al., 2014).

Diante do exposto, constitui-se um grupo de três zonas, cada qual com um terço do total dos papers proeminentes. A primeira zona contém um acanhado número 
de revistas altamente produtivas, a segunda sobrepuja um número maior de revistas que publicam menos, enquanto a terceira abarca um volume ainda maior de revistas com mínima produtividade sobre o tema (MACHADO JÚNIOR et al., 2014).

Em suma, a Lei de Bradford emite que a classificação decrescente de produtividade de manuscritos de determinado tema nas revistas científicas autoriza a afirmação de aglomerações divididas de forma exponencial. O número de periódicos em cada conjunto será proporcional a 1: $\mathrm{n}: \mathrm{n}^{2}$. Assim, mediante a medição da produtividade dos periódicos, é viável estabelecer o núcleo e os campos de dispersão sobre determinado tema em um mesmo grupo de periódicos (MACHADO JÚNIOR et al., 2014).

Em relação à Lei de Zipf ou Lei do Mínimo Esforço, esta o incide em aferir a constância do aparecimento das palavras em diversos textos, acendendo uma lista ordenada de termos de uma determinada matéria ou temática (MACHADO JÚNIOR et al., 2014).

Realça-se que apesar de as Leis de Lotka e Zipf serem essenciais para o embasamento teórico da bibliometria, elas não se constituem objeto de atenção deste trabalho, isto é, não são usadas para responder a eventuais dados e informações oriundos das aferições dos indicadores bibliométricos, pois não são mensurados dados e informações que remeterão às mencionadas Leis.

Em relação à rede social, entende-se que é uma representação gráfica das relações e interações entre os atores de um grupo e possui um objetivo essencial como meio de propagação de informações, ideias, conhecimento e influências (KIMURA; BASSO; MARTIN, 2008). Ressalta-se que os atores deste estudo são representados pelos periódicos, teorias e temas.

A centralidade é uma das propriedades da rede social que é utilizada com bastante frequência, envolvendo aspectos que se relacionam à importância ou visibilidade de um ator em uma determinada rede social (CRUZ et al., 2011b). Três são as medidas frequentemente empregadas para esse tipo de estimativa: centralidade de grau (degree), centralidade de proximidade (closeness) e centralidade de intermediação (betweenness) (ROSSONI; GUARIDO FILHO, 2009). Salienta-se que, para este estudo, somente será utilizada a centralidade de grau. Ela é compreendida como a medida do número de laços que um ator tem com outros atores em uma determinada rede social, contudo, contam-se somente os relacionamentos adjacentes, assim, tal aferição manifesta somente a centralidade local dos atores (ROSSONI; HOCAYEN-DA-SILVA; FERREIRA JÚNIOR, 2008), que no caso deste trabalho serão os periódicos, teorias e temas. 
Ainda evidenciando as redes sociais, realça-se que a técnica de análise two-mode é uma matriz bipartide, ou dois modos, utilizada nos casos em que existe mais de um grupo de atores. Nessa configuração, cada grupo de ator se dispõe em um dos eixos da matriz de relacionamento. Ressalta-se que a natureza dos dois conjuntos de atores até pode ser igual, contudo, os papéis desempenhados são divergentes (MACHADO JÚNIOR, 2012).

Alguns autores já publicaram seus estudos enfatizando a two-mode: Guarido Filho, Machado-da-Silva e Gonçalves (2010), Vedres e Stark (2010), Cruz et al. (2011b), Ribeiro (2013a), Ribeiro (2013b), Machado Júnior, Souza e Parisotto (2014). Nota-se que tais trabalhos que enfatizam a two-mode são bem recentes, o que nos faz entender que é uma metodologia ainda muito embrionária, sobretudo nos estudos da área de Administração, Contabilidade e Turismo no Brasil.

Para melhor entender e compreender a importância da bibliometria e da rede social no contexto de investigar a produção acadêmica de determinado campo do conhecimento e/ou temas científicos, por meio de indicadores, versam-se, a seguir, conceitos e relevância desses indicadores, tão importantes e necessários para a bibliometria e/ou rede social na aferição de dados e evidenciação de informações para análise, investigação, mapeamento, exploração da produção científica de assuntos acadêmicos e/ou áreas do saber das ciências.

\subsubsection{Indicadores de Produção Científica}

A utilização das técnicas da bibliometria no estudo da produção científica não é uma experiência nova, já que se verificam, no campo científico, diversos autores fazendo uso dos estudos bibliométricos para mensurar indicadores de produção científica (AMBONI; CAMINHA; ANDRADE, 2012). Os Indicadores de Produção Científica são construídos pela mensuração do número de publicações por tipo de documento, por exemplo: artigos científicos, por Instituições de Ensino Superior (IESs), área de conhecimento, país, etc. (KOBASHI; SANTOS, 2008).

Diante disso, realça-se que os indicadores de produção acadêmica vêm ganhando acuidade crescente como ferramenta para análise da atividade científica. Sua construção tem sido estimulada pelos órgãos de fomento à pesquisa como meio para se obter uma visão apurada da produção acadêmica de campos do conhecimento e/ ou temas científicos, de modo a ajudar a política científica e a avaliar seus resultados (KOBASHI; SANTOS, 2006). 
Diante do exposto, salienta-se que a bibliometria é uma técnica estatística utilizada para calcular aspectos da produção científica que contribui para o desenvolvimento da ciência (MEDEIROS; VITORIANO, 2015). Em suma, com a análise bibliométrica é viável construir indicadores de produção acadêmica que permitem conhecer a evolução de uma área do conhecimento e/ou tema científico, quantificar seus achados, aplicando-os em diferentes campos do saber (HAYASHI et al., 2012).

Esses indicadores de produção científica dividem-se em: indicadores de produção científica, arquitetados, por exemplo, pela apuração do número de publicações por tipo de documento e IES; de citação, colocados pela aferição do número de citações recebidas por uma publicação de manuscrito de periódico; e de ligação, criados pelos acontecimentos de autoria, citações e palavras, sendo aproveitados na preparação de mapas de estruturas de conhecimento e de redes sociais (ANJOS et al., 2015). Entende-se, com isso, que esses indicadores de produção científica também têm relação com a sociometria (ROSSONI; HOCAYEN-DA-SILVA, 2008) e que, portanto, são essenciais para aferir dados e informações que subsidiam pesquisas.

Nesse contexto, assumem-se como indicadores bibliométricos e sociométricos que nortearão o objetivo do presente estudo: evolução das Teorias na área de Administração, Contabilidade e Turismo; periódicos em destaque; teorias em destaque; temas em destaque; rede two-mode entre as Teorias em destaque e os periódicos relacionados a elas; rede two-mode entre as Teorias em destaque e os temas relacionados a elas; e, rede two-mode entre os temas em destaque e as Teorias relacionadas com eles.

\subsection{TEORIAS: IMPORTÂNCIA NO EMBASAMENTO TEÓRICO E DIFUSÃO DO CONHECIMENTO CIENTÍFICO}

Em relação ao objetivo deste estudo, constata-se que as teorias, de maneira geral, são essenciais para a construção do conhecimento científico na área de Administração (DJALÓ; PROCOPIUCK, 2010) e afins (GONDIM et al., 2005), cabendo ao pesquisador desafiar suas suposições e utilizá-las, objetivando a geração de insights (WHETTEN, 2003; KOVACS; MORAES; OLIVEIRA, 2011).

Nesse contexto, pode-se entender que as teorias são redes, difundidas para enlaçar aquilo que se denomina mundo, com o intuito de racionalizá-lo, elucidá-lo e contê-lo (LACERDA et al., 2013). Meneghetti (2011, p. 330) realça que:

A teoria, na ciência tradicional, expressa um conjunto de conceitos sistematicamente organizados e articulados, para criar um contexto cognoscível. Assim, a teoria apresenta-se como 
a expressão manifesta do pensar reificado, com conceitos baseados em fatos apresentados sistematicamente, de forma que sejam inteligíveis. Desta forma, a teoria tradicional, associada à ciência tradicional, é cognoscível, pois pressupõe o princípio da identidade.

Já Chiappin (1994, p. 40) evidencia que:

Uma Teoria da Ciência é uma estrutura composta de três níveis: metafísico, lógica da ciência e história. No nível metafísico descrevemos o domínio de estudo da teoria sendo reconstruída, assim como as características abstratas do conhecimento por ela proporcionado, os valores e os fins assumidos nesta área. No nível da lógica da ciência definimos os recursos metodológicos que descrevem como devemos construir a teoria e as explicações dos fenômenos estudados, assim como os métodos de escolha das teorias e das explicações construídas. Neste mesmo nível definimos também as características da legitimidade e justificação das concepções sendo elaboradas. No terceiro nível discutimos o papel que a história desempenha na concepção sendo reconstruída, se for o caso. O nível metafísico é composto, por sua vez, de três subníveis: o ontológico, onde ficam estabelecidas as principais entidades do domínio estudado; o epistemológico, onde são afirmadas as considerações sobre essas entidades e suas relações com os fenômenos; o axiológico, onde são afirmados os fins e os valores com os quais a concepção se encontra comprometida. O nível da lógica da ciência pode também ser dividido em dois subníveis: o metodológico (relativo à construção de teorias e explicações e à escolha entre elas) e o metamedológico.

Diante do colocado, Whetten (2003, p. 1), em seu estudo, enfatiza os blocos de construção para o desenvolvimento de Teoria, evidenciados no Quadro 1, ou seja, uma Teoria completa necessita focar e possuir quatro elementos fundamentais. 
Quadro 1 - Blocos de construção para o desenvolvimento de Teoria

\begin{tabular}{|c|c|c|c|}
\hline \multicolumn{4}{|c|}{ nto de Teoria } \\
\hline & mo & & \\
\hline $\begin{array}{l}\text { Quais fatores - va- } \\
\text { riáveis, construtos, } \\
\text { conceitos - logica- } \\
\text { mente devem ser } \\
\text { considerados como } \\
\text { parte da explicação } \\
\text { do fenômeno social } \\
\text { ou individual em } \\
\text { questão? Existem } \\
\text { dois critérios para } \\
\text { julgar se incluímos } \\
\text { os fatores “certos”: } \\
\text { abrangência - isto } \\
\text { é, todos os fatores } \\
\text { relevantes foram } \\
\text { incluídos? - e par- } \\
\text { cimônia - isto é, } \\
\text { alguns fatores devem } \\
\text { ser excluídos por } \\
\text { acrescentarem pouco } \\
\text { valor adicional para } \\
\text { nosso entendimento? }\end{array}$ & $\begin{array}{l}\text { Tendo identificado } \\
\text { um grupo de fatores, } \\
\text { a próxima pergunta } \\
\text { do pesquisador é: } \\
\text { como eles estão } \\
\text { relacionados? Ope- } \\
\text { racionalmente, isso } \\
\text { envolve usar “setas” } \\
\text { para conectar as } \\
\text { “caixas”. Esse passo } \\
\text { adiciona ordem à } \\
\text { conceitualização, } \\
\text { delineando padrões } \\
\text { explicitamente. Além } \\
\text { disso, ele tipicamente } \\
\text { introduz causalidade. } \\
\text { Apesar de o pes- } \\
\text { quisador poder não } \\
\text { estar apto para testar } \\
\text { adequadamente essas } \\
\text { conexões, restrições } \\
\text { nos métodos não } \\
\text { invalidam a natureza } \\
\text { causal inerente à }\end{array}$ & $\begin{array}{l}\text { A questão central aqui colo- } \\
\text { cada é: por que os colegas } \\
\text { deveriam dar crédito a essa } \\
\text { específica representação } \\
\text { do fenômeno? A resposta } \\
\text { pode ser encontrada na } \\
\text { lógica que fundamenta o } \\
\text { modelo. A solidez de visões } \\
\text { fundamentais na natureza } \\
\text { humana, de requisitos orga- } \\
\text { nizacionais ou de processos } \\
\text { sociais fornece a base para } \\
\text { o julgamento da racionali- } \\
\text { dade da conceitualização } \\
\text { proposta. }\end{array}$ & $\begin{array}{l}\text { Essas condições colocam } \\
\text { limitações nas proposições } \\
\text { geradas de um modelo teó- } \\
\text { rico. Tais fatores temporais } \\
\text { e contextuais delimitam as } \\
\text { fronteiras da generalização e, } \\
\text { assim, constituem o alcance } \\
\text { e a extensão da teoria. Estu- } \\
\text { diosos dos efeitos do tempo e } \\
\text { do contexto nas pessoas e nos } \\
\text { eventos continuam formulan- } \\
\text { do questões como “suas pre- } \\
\text { visões funcionariam no Japão, } \\
\text { com uma população operária } \\
\text { ou em períodos distintos de } \\
\text { tempo?”. Infelizmente, poucos } \\
\text { teóricos focam explicitamente } \\
\text { nos limites conceituais de suas } \\
\text { proposições. Em seus esforços } \\
\text { para entender um fenômeno } \\
\text { social, eles tendem a conside- } \\
\text { rá-lo somente em torno daqui- } \\
\text { lo que lhes é familiar e em um } \\
\text { período específico de tempo. }\end{array}$ \\
\hline
\end{tabular}

Fonte: Whetten (2003, p. 1).

Em suma, apesar de ser essencial que os teóricos sejam sensíveis ao cenário, as condições “quem”, “onde” e “quando” de uma teoria são caracteristicamente achadas mediante testes subsequentes das informações iniciais, que são oriundas das perguntas: “o quê”, “como” e "por quê". E, durante o procedimento de teste desses pensamentos e ideias em diferentes panoramas, descobrem-se as condições limitantes inerentes a ele. Porém, na carência dessas evidências experimentais, é necessário ser realista no que se refere a todas as aceitáveis limitações da aplicabilidade de uma teoria (WHETTEN, 2003).

Pode-se compreender que uma teoria é importante por causa de sua influência no direcionamento dos interesses de pesquisa e no seu sucesso em se converter em paradigma (BERTERO, 1975). Nesse caso, é importante realçar que o grau de importância de uma teoria é aferido pelo seu poder de previsibilidade, ou seja, teorias que são fal- 
seadas constantemente em virtude de seu fraco poder de previsão não deveriam ser classificadas no rol das teorias que são mais bem fundamentadas (BASSO; PACE, 2003).

Diante do exposto, evidenciam-se, a seguir, algumas teorias da área de Administração e afins, que são destaque neste estudo e que fornecem sustentação teórica aos trabalhos publicados nesse campo do conhecimento.

A Teoria Institucional é uma abordagem sociológica (BARBOSA NETO; COLAUTO, 2010) que vem se tornando uma opção aos enfoques clássicos os quais realçavam apenas os aspectos racionais arrolados à eficiência e à eficácia das empresas. A mencionada Teoria veio comprovar que os intercâmbios simbólicos também impactam um procedimento de processo de decisão, de forma que valores e crenças divididas alcançam uma acuidade peculiar em prejuízo da razão (LORÊTO; PACHECO, 2007).

Já a Teoria das Restrições surgiu em 1970, e nela busca-se versar como respeitáveis apenas os pontos do gargalo e não todos os pontos dentro de qualquer organização, pois se visa melhorar o desempenho contínuo de qualquer organização (CRUZ et al., 2010). A referida Teoria contempla uma forma diferente em conceitos antes legitimados: a passagem do foco do custo para o do ganho extraordinário. Além disso, auxilia as organizações ocidentais a minimizarem o gap tecnológico em comparação às empresas orientais. Verifica-se que a acenada Teoria é vigorosa, intensa, motivadora, pungente, consentindo, assim, alterações estruturais nos mercados corporativos ocidentais.

O pressuposto básico subjacente à Teoria da Agência é o de que as grandes corporações de capital aberto compõem um conjunto de contratos cujo desígnio é o de elevar ao máximo a riqueza dos acionistas. Esses contratos são firmados entre um agente interno (gestor) e um agente externo, ou seja, o principal (acionistas), e estão associados à delegação de poder (JENSEN; MECKLING, 1976). Disso pode surgir o problema do conflito de interesse, que é um dos focos da citada Teoria, pois tal conflito costuma ocorrer entre o principal e o agente, em especial quando as iniciativas executadas pelo agente são difíceis de serem observadas por aquele que as delega, o principal (MARTINS; SOUZA, 2014), surgindo a assimetria informacional (ROCHA et al., 2012).

No que se refere à Teoria da Contabilidade, verifica-se que ela é proeminente para os pesquisadores e para aqueles envolvidos em processos práticos pautados pela Contabilidade (FUJI; SLOMSKI, 2003). Em suma, é considerada uma área de pesquisa essencial para os acadêmicos (OLIVEIRA, 2002), sobretudo porque ajuda a compreender a Contabilidade como uma ciência capaz de explicar e predizer fenômenos (SILVA; ZUCCOLOTTO, 2014).

A Teoria dos Jogos é o estudo da conduta de jogadores racionais em intercâmbio dentro de um ambiente estratégico, desenvolvendo discernimentos racionais 
para a seleção de uma estratégia, e isso é feito dentro da conjectura de que os jogadores sejam racionais, e de que cada um tentará, invariavelmente, fazer o melhor que puder em relação a seu adversário (SANTOS, 2003).

Em relação à Teoria dos Custos de Transação, entende-se que é uma vertente da Nova Economia Institucional (ARRUDA et al., 2013), a qual parte da conjectura de que as interações no ambiente organizacional apresentam custos que não podem ser abandonados. Diante do exposto, observa-se que a aludida Teoria se centra em que a análise das empresas são as transações nas quais estão abrangidas com seus respectivos custos de transação, que norteiam o mercado corporativo (CRUZ et al., 2011a) e, consequentemente, os negócios internacionais (FERREIRA; PINTO; SERRA, 2013).

A Teoria dos Stakeholders somente madurou nos últimos anos (FASSIN, 2010). Salienta-se que a primeira aparição do termo stakeholder no campo da Administração ocorreu em um memorando interno do Instituto de Pesquisa de Stanford (IPS) em 1963 (FREEMAN; REED, 1983). Porém, a designação do citado termo foi difundida por Freeman e Reed no meio acadêmico somente em 1983 (FREEMAN; REED, 1983), sendo adotado pela maioria dos acadêmicos, contribuindo, assim, para a aceitação do mencionado termo no meio empresarial (FASSIN, 2008).

Observando-se as teorias colocadas em evidência e contempladas nos parágrafos anteriores, constata-se que todas elas têm suas respectivas importâncias no contexto acadêmico e empresarial, e que, no decorrer dos anos, vêm evoluindo e se tornando nortes essenciais e partes preponderantes para os acadêmicos, usando-as de maneira coerente e equilibrada para embasar seus estudos, publicá-los e difundi-los na literatura acadêmica internacional, criando, consequentemente, conhecimentos científicos, que são essenciais para se tornarem parte fundamental na prática empresarial das organizações no mercado corporativo global.

\section{PROCEDIMENTOS METOdOLÓGICOS}

O objetivo neste estudo foi investigar a produção acadêmica de Teorias colocadas em evidência nos estudos divulgados nos periódicos nacionais da área de Administração, Contabilidade e Turismo entre 1999 e 2013. Para isso, neste trabalho são focadas as técnicas de análise bibliométrica e de rede social (RIBEIRO; COSTA; FERREIRA, 2014); esta última coloca em evidência a técnica de rede two-mode (RIBEIRO, 2013a).

Para se investigar a pesquisa bibliométrica e sociométrica sobre as Teorias colocadas em evidência nos 364 estudos identificados, foram escolhidos os periódicos nacionais com a classificação A1, A2, B1 e B2 pela Qualis Capes da área de 
Administração, Contabilidade e Turismo (triênio 2010-2012). Esses são os extratos elevados de aferição dos indicadores bibliométricos e sociométricos, por meio de seus respectivos estudos divulgados, desta pesquisa. Diante do exposto, chegou-se à relação considerada no Quadro 2.

Quadro 2 - Classificação dos periódicos (triênio) (2010-2012)

\begin{tabular}{|c|c|c|c|}
\hline Revista & Sigla & ISSN & Nota \\
\hline Brazilian Administration Review & BAR & $1807-7692$ & A2 \\
\hline Brazilian Business Review & BBR & $1807-734 X$ & A2 \\
\hline Gestão \& Produção & G\&P & 1806-9649 ou 0104-530X & A2 \\
\hline RAC Eletrônica & RAC-e & $1981-5700$ & A2 \\
\hline Revista de Administração Contemporânea & RAC & $1415-6555$ ou 1982-7849 & A2 \\
\hline RAE Eletrônica & RAE-e & $1676-5648$ & A2 \\
\hline Revista de Administração de Empresas & RAE & 0034-7590 ou 2178-938X & A2 \\
\hline Rausp-e & Rausp-e & $1983-7488$ & A2 \\
\hline Revista Brasileira de Economia & $\mathrm{RBE}$ & 0034-7140 & A2 \\
\hline Revista Contabilidade \& Finanças & RC\&F & 1519-7077 ou 1808-057X & $\mathrm{A} 2$ \\
\hline Revista de Administração da USP & Rausp & 0080-2107 ou 1984-6142 & A2 \\
\hline Revista de Administração Pública & RAP & $0034-7612$ & A2 \\
\hline Revista Base & BASE & 1984-8196 ou 1807-054X & B1 \\
\hline Cadernos EBAPE.BR & Ebape & $1679-3951$ & B1 \\
\hline Contabilidade Vista \& Revista & CV\&R & 0103-734X & B1 \\
\hline Contexto Internacional & CI & $0102-8529$ & B1 \\
\hline Economia Aplicada & EA & $1413-8050$ & B1 \\
\hline Economia e Sociedade & ES & 0104-0618 & B1 \\
\hline Economia Global e Gestão & EGG & 0873-7444 & B1 \\
\hline Estudos Econômicos & EE & 0101-4161 & B1 \\
\hline Faces: Revista de Administração & Faces & $1517-8900$ ou $1984-6975$ & B1 \\
\hline Gestão \& Regionalidade & G\&R & $1808-5792$ ou $2176-5308$ & B1 \\
\hline Produção & Prod. & 1980-5411 ou 0103-6513 & B1 \\
\hline Nova Economia & $\mathrm{NE}$ & $0103-6351$ & B1 \\
\hline Revista de Administração e Inovação & RAI & 1809-2039 & B1 \\
\hline Revista de Administração Mackenzie & RAM & $1518-6776$ ou $1678-6971$ & B1 \\
\hline Revista Eletrônica de Administração & READ & $1413-2311$ ou $1980-4164$ & B1 \\
\hline Revista Brasileira de Finanças & RBF & $1679-0731$ ou $1984-5146$ & B1 \\
\hline Revista Brasileira de Gestão de Negócios & RBGN & $1983-0807$ ou $1806-4892$ & B1 \\
\hline Revista Brasileira de Pesquisa em Turismo & Rbtur & $1982-6125$ & B1 \\
\hline Revista Contemporânea de Contabilidade & RCC & $2175-8069$ ou $1807-1821$ & B1 \\
\hline Revista de Administração da UFSM & $\operatorname{ReA}$ & $1983-4659$ & B1 \\
\hline Revista de administração da Unimep & RAU & $1679-5350$ & B1 \\
\hline Revista de Ciências da Administração & RCA & 2175-8077 ou 1516-3865 & B1 \\
\hline Revista de Contabilidade e Organizações & RCO & $1982-6486$ & B1 \\
\hline Revista de Economia Contemporânea & REC & $1415-9848$ & B1 \\
\hline Revista de Economia Política & REP & 0101-3157 ou 1809-4538 & B1 \\
\hline Revista Universo Contábil & RUC & 1809-3337 & B1 \\
\hline Advances in Scientific and Applied Accounting & ASAA & $1983-8611$ & B2 \\
\hline
\end{tabular}




\begin{tabular}{|l|l|l|l|}
\hline Contabilidade, Gestão e Governança & CGG & $1984-3925$ & B2 \\
\hline Contextus & Contextus & $1678-2089$ & B2 \\
\hline Enfoque: Reflexão Contábil & ERC & $1517-9087$ & B2 \\
\hline Gestão e Planejamento & GeP & $2178-8030$ & B2 \\
\hline Internext & Inter & $1980-4865$ & B2 \\
\hline Organizações em Contexto & OC & $1809-1040$ ou 1982-8756 & B2 \\
\hline Perspectivas Contemporâneas & PC & $1980-0193$ & B2 \\
\hline Pretexto & PRET. & $1517-672$ X ou 1984-6983 & B2 \\
\hline $\begin{array}{l}\text { Revista de Administração, Contabilidade e Econo- } \\
\text { mia }\end{array}$ & RACE & $1678-6483$ ou 2179-4936 & B2 \\
\hline Revista Brasileira de Estratégia & Rebrae & $1983-8484$ & B2 \\
\hline Revista Eletrônica de Ciência Administrativa & Recadm & $1677-7387$ & B2 \\
\hline Revista de Gestão da USP & REGE & $2177-8736$ ou 1809-2276 & B2 \\
\hline Revista Alcance & Alcance & $1983-716$ X & B2 \\
\hline Revista Ambiente Contábil & Racont & $2176-9036$ & B2 \\
\hline Revista de Educação e Pesquisa em Contabilidade & Repec & $1981-8610$ & B2 \\
\hline Revista Economia \& Gestão & E\&G & $1984-6606$ & B2 \\
\hline Revista Ibero-americana de Estratégia & RIAE & $2176-0756$ & B2 \\
\hline $\begin{array}{l}\text { Revista Pensamento Contemporâneo em Adminis- } \\
\text { tração }\end{array}$ & RPCA & $1982-2596$ & B2 \\
\hline Revista de Gestão Organizacional & RGO & $1806-6720$ ou 1983-6635 & B2 \\
\hline Revista de Gestão Social e Ambiental & RGSA & $1981-982 X$ & B2 \\
\hline Sociedade, Contabilidade e Gestão & SCG & $1982-7342$ & B2 \\
\hline
\end{tabular}

Fonte: os autores.

No Quadro 2 observam-se os 60 periódicos científicos investigados neste estudo. A coleta de dados foi realizada procurando-se, nessas revistas, manuscritos publicados entre 1999 e 2013. Cada um desses periódicos contemplados no Quadro 2 adveio de um procedimento de busca de artigos que contentassem o objetivo geral deste estudo. Em todos os papers publicados, a acessibilidade deles foi em meio eletrônico. Os artigos cunhados foram acessados diretamente dos respectivos sites dessas revistas; a procura foi realizada de forma a se encontrarem todos os estudos que contivessem as palavras-chave Teoria e/ou Theory no título.

Realça-se que foi aconselhada a busca somente no título pelas palavras-chave anteriormente citadas por se crer que por meio desse processo seriam encontrados os manuscritos que contemplassem diretamente informações sobre o tema ora mapeado, minimizando, com isso, possíveis gaps, equívocos e/ou incoerências em entrar nas mensurações bibliométricas e sociométricas, artigos que não continham relação direta com o tema Teorias. Observa-se que as palavras-chave não foram apuradas de forma simultânea. Esse artifício consentiu que fossem eleitos todos os papers que apresentassem ao menos uma das palavras-chave antes consideradas. Com isso, foram localizados 422 manuscritos, porém, depois de estes passarem por um processo de 
“pente-fino”, para se constatar se todos eles tinham relação direta com o objetivo desta pesquisa, foi ratificado, chegando-se ao número final de 364 trabalhos.

Em suma, a coleta de dados identificou 364 estudos, que foram investigados de maneira quantitativa. Os dados sobre cada artigo foram transformados em informações e capturados usando-se o software Bibexcel, e as visualizações das figuras foram feitas usando-se os softwares UCINET 6 for Windows e Microsoft Excel 2007.

\section{ANÁLISE E DISCUSSÃO DOS RESULTADOS}

Analisando-se o Gráfico 1, verifica-se certa evolução de artigos que enfatizam e colocam em evidência teorias, sobretudo das áreas de Administração e Contabilidade. Esse crescimento ocorre em especial a partir de 2005, tendo o seu ápice em 2013.

Tal achado contribui para mostrar que, apesar de serem importantes e balizadoras de pesquisas científicas, as teorias que as alicerçam, ou seja, os pilares, somente começaram recentemente, de fato, a serem colocadas em maior realce nos papers aqui investigados, o que faz entender que os trabalhos que usam essas estratégias ficam, de maneira geral, mais robustos e, de maneira macro, mais protegidos e segurados referente à melhor compreensão dos eventos e aspectos que cada um dos 364 estudos identificados e investigados neste trabalho trazem em todas as suas nuances e no seu bojo teórico.

Gráfico 1 - Evolução das Teorias na área de Administração, Contabilidade e Turismo

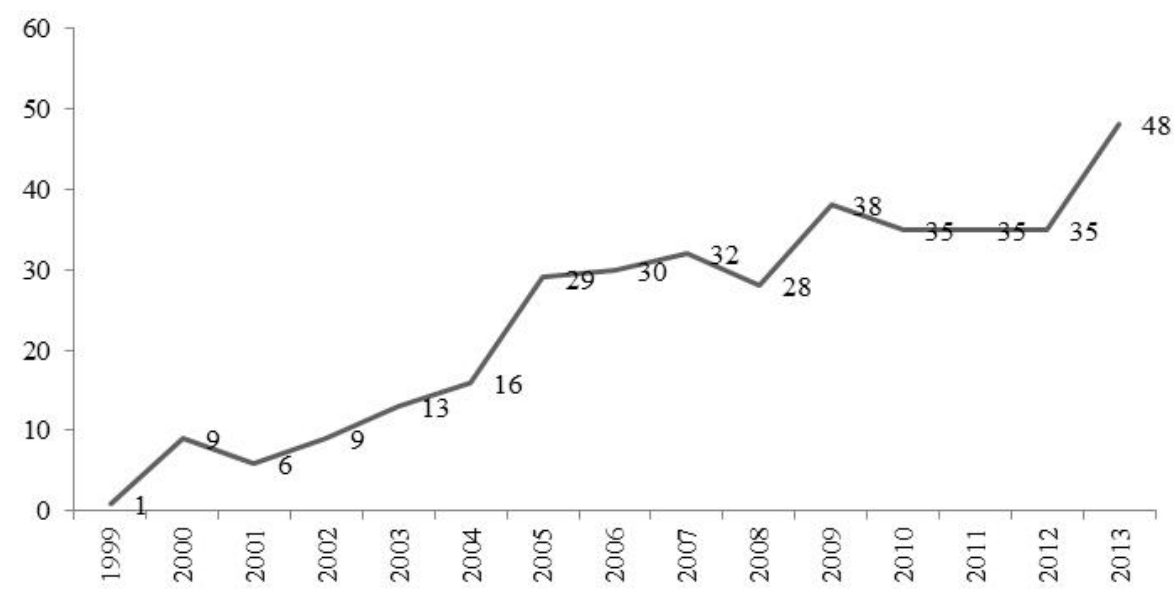

Fonte: os autores. 
A Tabela 1 contempla os 58 periódicos que, em suas publicações, em seus respectivos títulos, colocaram em destaque diversas teorias, sobretudo dos campos de Administração e Contabilidade.

Tabela 1 - Periódicos em destaque

(continua)

\begin{tabular}{|c|c|c|c|c|c|c|c|c|c|c|c|c|c|c|c|c|}
\hline Periódicos/Anos & 99 & 00 & 01 & 02 & 03 & 04 & 05 & 06 & 07 & 08 & 09 & 10 & 11 & 12 & 13 & Total \\
\hline EBAPE & & & & & & 2 & 2 & 3 & & 2 & 3 & 3 & 3 & 1 & 3 & 22 \\
\hline RAM & & & & & 1 & & 2 & 2 & 1 & 2 & 2 & 1 & 2 & 1 & 3 & 17 \\
\hline RAC & & 1 & & 1 & 3 & 2 & 1 & & 4 & 1 & & 2 & 1 & & & 16 \\
\hline RAE & & 2 & & & & & 1 & 5 & 3 & 2 & & 1 & & 2 & & 16 \\
\hline REGE & & 2 & 3 & 2 & 1 & 1 & 2 & & 2 & 1 & & & & 1 & & 15 \\
\hline REAd & & & & 3 & & 1 & 2 & 1 & 1 & & 2 & & & 1 & 1 & 12 \\
\hline BASE & & & & & & & 1 & & & 2 & 1 & 1 & 1 & 2 & 2 & 10 \\
\hline BBR & & & & & & 1 & 3 & 1 & & 1 & & & 1 & 1 & 2 & 10 \\
\hline RAU & & & & & & 2 & & 1 & 2 & & 1 & 1 & 1 & & 2 & 10 \\
\hline Rausp & & 1 & 1 & & 1 & 1 & 2 & 1 & & & & 2 & & 1 & & 10 \\
\hline REP & & & & & & & & 2 & & 1 & 3 & & & 2 & 2 & 10 \\
\hline RC\&F & & & 1 & 1 & & & 1 & 2 & 1 & & & 1 & & 1 & 1 & 9 \\
\hline BAR & & & & & & & & 3 & 3 & & & 1 & 1 & & & 8 \\
\hline G\&P & & & & 1 & & & & & & & & 1 & 3 & 2 & 1 & 8 \\
\hline RAI & & & & & & & & 1 & 1 & 1 & 1 & 1 & 1 & & 2 & 8 \\
\hline RBE & & 1 & 1 & 1 & 1 & 1 & 1 & & & & & & & & 2 & 8 \\
\hline RBGN & & & & & & & & & 2 & 3 & 2 & & 1 & & & 8 \\
\hline RGeP & & & & & & & & & & & 1 & 1 & 2 & 3 & 1 & 8 \\
\hline Alcance & & & & & 1 & & & & 1 & & & 2 & & & 3 & 7 \\
\hline $\mathrm{EE}$ & & & & & 1 & 1 & 2 & 1 & & & & 1 & & & 1 & 7 \\
\hline Faces & & & & & & & & 1 & & 1 & 1 & & 2 & 1 & 1 & 7 \\
\hline RAP & & & & & & & & & 1 & 1 & 1 & & & 3 & 1 & 7 \\
\hline Recadm & & & & & & 1 & 1 & 1 & 1 & & & 1 & & 1 & 1 & 7 \\
\hline RGO & & & & & & & & & & 1 & & & 1 & & 5 & 7 \\
\hline RUC & & & & & & & 1 & & & & & 3 & & & 2 & 6 \\
\hline CGG & & 1 & & & 1 & & & & & & 1 & & 2 & & & 5 \\
\hline CV\&R & & 1 & & & 1 & & & & & & 1 & 1 & 1 & & & 5 \\
\hline ERC & & & & & & & & & 1 & & 2 & & 1 & & 1 & 5 \\
\hline Internext & & & & & & & & 1 & & 1 & 1 & & & & 2 & 5 \\
\hline RAE-e & & & & & & 1 & 3 & & & 1 & & & & & & 5 \\
\hline RCA & 1 & & & & & & 1 & 1 & & & & & & & 2 & 5 \\
\hline ReA & & & & & & & & & & 1 & 2 & 1 & & & 1 & 5 \\
\hline Repec & & & & & & & & & 1 & & 2 & & & 2 & & 5 \\
\hline ASAA & & & & & & & & & & & & 1 & 1 & 2 & & 4 \\
\hline Contextus & & & & & 1 & 1 & & 1 & & & & & 1 & & & 4 \\
\hline ES & & & & & & & & & & 1 & & 1 & & 2 & & 4 \\
\hline PC & & & & & & & & 2 & & & & 1 & 1 & & & 4 \\
\hline Produção & & & & & & & 1 & & 1 & & & & 1 & & 1 & 4 \\
\hline RACont & & & & & & & & & & & 2 & & & 1 & 1 & 4 \\
\hline RCC & & & & & & 1 & & & 1 & & 2 & & & & & 4 \\
\hline
\end{tabular}




\begin{tabular}{|c|c|c|c|c|c|c|c|c|c|c|c|c|c|c|c|c|}
\hline & & & & & & & & & & & & & & & \multicolumn{2}{|c|}{ (conclusão } \\
\hline Periódicos/Anos & 99 & 00 & 01 & 02 & 03 & 04 & 05 & 06 & 07 & 08 & 09 & 10 & 11 & 12 & 13 & Total \\
\hline RCO & & & & & & & & & 1 & 1 & 1 & & & & 1 & 4 \\
\hline RPCA & & & & & & & & & 1 & & & & 1 & 1 & 1 & 4 \\
\hline SCG & & & & & & & & & & 1 & 1 & & 1 & & 1 & 4 \\
\hline EGG & & & & & & & & & & & 1 & 1 & 1 & & & 3 \\
\hline OC & & & & & & & & & 1 & & & 1 & & 1 & & 3 \\
\hline RACE & & & & & & & & & & & & 1 & 1 & & 1 & 3 \\
\hline RAC-e & & & & & & & & & 1 & 2 & & & & & & 3 \\
\hline REC & & & & & & & & & 1 & & & 1 & & 1 & & 3 \\
\hline RIAE & & & & & & & & & & & 2 & & 1 & & & 3 \\
\hline G\&R & & & & & & & & & & & & 2 & & & & 2 \\
\hline NE & & & & & & & 2 & & & & & & & & & 2 \\
\hline Pretexto & & & & & & & & & & & 1 & & & 1 & & 2 \\
\hline RGSA & & & & & & & & & & & & 1 & 1 & & & 2 \\
\hline EA & & & & & & & & & & 1 & & & & & & 1 \\
\hline RBF & & & & & 1 & & & & & & & & & & & 1 \\
\hline Rbtur & & & & & & & & & & & & & & 1 & & 1 \\
\hline$E \& G$ & & & & & & & & & & & & & 1 & & & 1 \\
\hline Rebrae & & & & & & & & & & & 1 & & & & & 1 \\
\hline Total & 1 & 9 & 6 & 9 & 13 & 16 & 29 & 30 & 32 & 28 & 38 & 35 & 35 & 35 & 48 & 364 \\
\hline
\end{tabular}

Fonte: os autores.

O periódico EBAPE foi o que se destacou nesta seção, com 22 artigos publicados; em seguida foi o periódico RAM, com 17 publicações; com 16 papers estão as revistas RAC e RAE; a REGE publicou 15 manuscritos, e a revista REAd divulgou 12 artigos. E com 10, estão os meios de comunicação: BASE, BBR, RAU, Rausp e REP. Dessas 11 revistas, oito são da área da Administração, duas do campo Contábil e uma voltada à Economia, somando, com isso, um total de 148 artigos sobre o assunto em investigação, o que equivale a 40,66\% do montante de 364 publicações.

Destacam-se, também, as revistas RC\&F, com 9 artigos, BAR, G\&P, RAI, RBE, RBGN, RGeP, com 8, Alcance, Estudos Econômicos, Faces, RAP, Recadm, RGO, com seis, e RUC, com seis publicações. Salienta-se que dessas revistas, 10 são do campo da Administração, duas são da área Contábil e duas são relacionadas à Economia, totalizando 105 manuscritos, em um percentual de 28,85\% do total dos papers identificados. E, por fim, os demais 33 periódicos que publicaram de cinco a um artigos sobre o assunto em investigação, totalizando 111 manuscritos, ou seja, 30,49\% do total.

As informações evidenciadas nesta seção nos parágrafos anteriores vão ao encontro do que prega a Lei de Bradford (SOUZA; RIBEIRO, 2013), pois mensuram o nível de valor de revistas em um campo científico, ou seja, os periódicos que publicam o maior número de estudos sobre um tema formam um núcleo de periódicos, 
com destaque para o citado campo do conhecimento e tema científico (BEUREN; SOUZA, 2008).

Esses núcleos podem ser vistos com realce nesta seção, pois o primeiro contempla um baixo número de periódicos, contudo, estes são altamente produtivos, são eles: Ebape, RAM, RAC, RAE, REGE, REAd, BASE, BBR, RAU, Rausp e REP. O segundo evidencia um número um pouco maior de periódicos que publicam menos, são eles: RC\&F, BAR, G\&P, RAI, RBE, RBGN, RGeP, Alcance, EE, Faces, RAP, Recadm, RGO e RUC. Por fim, o terceiro núcleo abrange um volume ainda maior de revistas, porém com uma produtividade sobre o tema em destaque ainda menor, que são: CGG, CV\&R, ERC, Internext, RAE-e, RCA, ReA, Repec, ASAA, Contextus, ES, PC, Produção, RACont, RCC, RCO, RPCA, SCG, EGG, OC, RACE, RAC-e, REC, RIAE, G\&R, NE, Pretexto, RGSA, EA, RBF, Rbtur, E\&G e Rebrae.

Em suma, esses achados contribuem para evidenciar o grau de importância desses periódicos no que se refere às suas respectivas produtividades quanto ao tema em investigação. E que, apesar de $97 \%$ das revistas publicarem ao menos um artigo sobre o assunto ora estudado, elas estão divididas em núcleos, que correspondem aos níveis de acuidade que cada um tem no conhecimento científico sobre teorias diversas. Nesse contexto, ressalta-se a preponderância desses meios de comunicação para a difusão da Ciência, mesmo que classificados em ordem de realce, mas, de forma geral, isto é, de suma importância para a socialização do saber científico, em especial, quando versam teorias que são alicerces, pilares, ou seja, responsáveis de maneira macro pelo embasamento e legitimidade dos estudos publicados e divulgados na literatura acadêmica, nesse caso, a nacional. Na Tabela 2 são presentadas as 17 Teorias que se destacaram neste estudo.

Tabela 2 - Teorias em destaque

(continua)

\begin{tabular}{|c|c|c|c|c|c|c|c|c|c|c|c|c|c|c|c|c|}
\hline Teorias/Anos & 99 & 00 & 01 & 02 & 03 & 04 & 05 & 06 & 07 & 08 & 09 & 10 & 11 & 12 & 13 & Total \\
\hline Teoria Institucional & & & & & & & 3 & 5 & 6 & 2 & 2 & 4 & & 5 & 5 & 32 \\
\hline Teoria das Restrições & & & & & & 2 & 2 & 1 & 1 & 1 & 3 & 2 & 1 & 2 & 2 & 17 \\
\hline Teoria Organizacional & 1 & 1 & & 1 & 1 & 3 & 2 & 3 & & & & 2 & 1 & & & 15 \\
\hline Teoria da Agência & & & 1 & & & 1 & 1 & 1 & 2 & 3 & 1 & & 1 & 1 & 1 & 13 \\
\hline Teoria da Contabilidade & & 1 & & & 1 & & 1 & & 1 & & 3 & 1 & 1 & 2 & 1 & 12 \\
\hline Teoria dos Jogos & & & & 1 & 1 & & & 1 & & 2 & 2 & & 2 & & 2 & 11 \\
\hline Grounded Theory & & & & & & & & & 1 & 2 & 2 & & 2 & & 1 & 8 \\
\hline Teoria da Resposta ao Item & & & & 1 & & & & & & & & & 3 & 1 & 3 & 8 \\
\hline Teoria de Redes & & & & & & 1 & & & & & 2 & & 2 & & 3 & 8 \\
\hline Teoria dos Custos de Transação & & & & & & & 1 & 2 & & & & 1 & 2 & & 2 & 8 \\
\hline Teoria dos Prospectos & & & & & & & & & 1 & 1 & 2 & 1 & 1 & 1 & & 7 \\
\hline Teoria dos Stakeholders & & & & & 1 & & 1 & & 1 & 1 & & 1 & & & 2 & 7 \\
\hline
\end{tabular}


(conclusão)

\begin{tabular}{|c|c|c|c|c|c|c|c|c|c|c|c|c|c|c|c|c|}
\hline Teorias/Anos & 99 & 00 & 01 & 02 & 03 & 04 & 05 & 06 & 07 & 08 & 09 & 10 & 11 & 12 & 13 & Total \\
\hline Teoria do Capital Humano & & & & & & & 1 & & & & 1 & 2 & & & 2 & 6 \\
\hline $\begin{array}{l}\text { Teoria dos Recursos e Capa- } \\
\text { cidades }\end{array}$ & & & & 1 & & & & 2 & & & 2 & & & 1 & & 6 \\
\hline Teoria da Administração & & & & & 2 & & & & & & & 1 & 1 & & 1 & 5 \\
\hline Teoria da Firma & & & & & & & & 1 & 1 & 2 & 1 & & & & & 5 \\
\hline Teorias da Internacionalização & & & & & & & & 1 & 1 & & 1 & & & & 2 & 5 \\
\hline 9 Teorias publicadas 4 vezes & & & & & & & & & & & & & & & & 36 \\
\hline 6 Teorias publicadas 3 vezes & & & & & & & & & & & & & & & & 18 \\
\hline 19 Teorias publicadas 2 vezes & & & & & & & & & & & & & & & & 38 \\
\hline 99 Teorias publicadas $1 \mathrm{vez}$ & & & & & & & & & & & & & & & & 99 \\
\hline Total & & & & & & & & & & & & & & & & 364 \\
\hline
\end{tabular}

Fonte: os autores.

A Teoria Institucional se destacou neste estudo, sendo publicada com ênfase em 32 trabalhos; tal feito pode estar relacionado à sua robustez nos estudos organizacionais (MISOCZKY, 2003). Observa-se que essa Teoria ganha espaço nos estudos organizacionais por munir formas de compreender padrões subentendidos e heterogeneidade dentro das organizações (PEREIRA, 2012).

Logo em seguida veio a Teoria das Restrições, com 17 publicações colocando-a em destaque, em virtude de sua filosofia de melhora contínua na avaliação do desempenho no âmbito do controle de produção na gestão (GIACON; MESQUITA, 2011). Em suma, essa Teoria merece especial atenção de pesquisadores e de profissionais da prática da gestão organizacional (PLANTULLO, 1994).

A Teoria Organizacional apresentou 15 publicações. Essa ênfase na citada Teoria ocorreu em virtude de ela representar fortemente um produto da cultura na organização (RODRIGUES; CARRIERI, 2001). A Teoria da Agência veio em seguida, com 13 papers, e seu realce deve-se à sua relação direta com a governança corporativa, impulsionando-a no âmbito corporativo e acadêmico (RODRIGUES; MALO, 2006). Nesse contexto, evidencia-se a questão de agência que é refletida pelo problema de agência, um dos enfoques da citada Teoria. Em outras palavras, surgem possíveis conflitos, que costumam ocorrer entre o proprietário e o gestor, sobretudo quando as iniciativas executadas pelo executivo principal são difíceis de serem verificadas por aquele que as delega, o proprietário (MARTINS; SOUZA, 2014), aparecendo, assim, a falta de transparência das informações (ROCHA et al., 2012).

Com 12 artigos apareceu a Teoria da Contabilidade; sua evidência neste estudo ocorreu em virtude de sua importância como pressuposto essencial nas Ciências Contábeis, ao atender, de maneira eficaz e eficiente, aos usuários que dela necessitam (GUERREIRO; CORNACHIONE JÚNIOR; SOUTES, 2011). Tal Teoria é vista, também, como 
uma oportunidade de pesquisa essencial para os acadêmicos (OLIVEIRA, 2002), em especial, por ajudar a entender e a compreender a Contabilidade como uma Ciência capaz de difundir e evidenciar fenômenos contábeis (SILVA; ZUCCOLOTTO, 2014).

Já a Teoria dos Jogos teve 11 artigos divulgados; tal relevo pode ser por ocasião de sua importância como abordagem teórica interdisciplinar para estudos estratégicos (ANDRADE, 2002). De maneira geral, tal Teoria estuda a conduta de jogadores racionais em intercâmbio dentro de um cenário estratégico, aperfeiçoando discernimentos racionais para a seleção de uma estratégia, ou seja, essa teoria versa conjecturas de que os jogadores necessitam ser racionais, e de que cada um buscará, inevitavelmente, realizar o melhor que puder em relação a seu adversário (SANTOS, 2003).

Ainda analisando a Tabela 2, observam-se outras Teorias que ficaram em realce: Grounded Theory por ser um método de pesquisa qualitativa, com o objetivo de desenvolver teorias à medida que o estudo de campo avança (NEVES; CONEJERO, 2012). A Teoria da Resposta ao Item, por ser usada universalmente como ferramenta de avaliação organizacional (BORTOLOTTI et al., 2012). A Teoria de Redes, que permite entender e compreender relações e afinidades entre atores coletivos e individuais (LOPES; BALDI, 2009). A Teoria dos Custos de Transação, por encadear seu foco nos contratos das firmas como também o faz a Teoria da Agência (BATISTA et al., 2011). Enfatiza-se, também, a Teoria dos Prospectos, por sua importância para melhor entender os processos decisórios, evitando-se, com isso, as situações de risco em uma organização (CAPPELLOZZA; SANCHEZ, 2011).

A Teoria dos Stakeholders somente amadureceu nos últimos anos (FASSIN, 2010). Realça-se que o surgimento do termo stakeholder no campo da Administração ocorreu em um memorando interno do IPS em 1963 (FREEMAN; REED, 1983). Entretanto, a nomenclatura do referido termo foi evidenciada por Freeman e Reed no meio da literatura científica internacional somente em 1983 (FREEMAN; REED, 1983), sendo adotada pela grande maioria dos pesquisadores, cooperando, assim, para a aceitação do citado termo no meio corporativo (FASSIN, 2008). É bom salientar a relevância da mencionada Teoria, por ser, atualmente, amplamente debatida em trabalhos com foco na responsabilidade social corporativa (CALIXTO, 2013).

A Teoria do Capital Humano deve ser citada por nortear o valor do capital humano das pessoas, mediante seus conhecimentos, habilidades e competências (CUNHA; CORNACHIONE JÚNIOR; MARTINS, 2010). A Teoria da Administração, por ser vista como a Ciência Social; a Teoria da Firma, por embasar em parte a Teoria da Agência (JENSEN; MECKLING, 1976). E, por fim, as Teorias da Interna- 
cionalização por darem sustentação teórica ao tema internacionalização (MACHADO NETO; ALMEIDA, 2008).

Ainda, cabe ressalvar que 133 Teorias foram publicadas de uma a quatro vezes, o que de fato é um resultado que evidencia uma oportunidade grande de manifestar tais teorias de maneira mais macro, difundindo suas respectivas importâncias para o embasamento teórico e a socialização do conhecimento científico nas áreas investigadas neste trabalho.

A Tabela 3 contempla os 12 temas em destaque neste estudo. Na citada Tabela, dados e informações foram criados por se observar que as teorias identificadas neste estudo traziam temas que se embasavam nestas, e, com isso, verificou-se ser importante também trazer à tona esses assuntos para esta pesquisa.

Tabela 3 - Temas em destaque

\begin{tabular}{|c|c|c|c|c|c|c|c|c|c|c|c|c|c|c|c|c|}
\hline Teorias/Anos & 99 & 00 & 01 & 02 & 03 & 04 & 05 & 06 & 07 & 08 & 09 & 10 & 11 & 12 & 13 & Total \\
\hline Estratégia organizacional & & & & 2 & 2 & & 2 & 4 & 4 & 1 & 4 & 2 & 5 & 3 & 4 & 33 \\
\hline Marketing & & & & & & & & 4 & 1 & 3 & 1 & 2 & 5 & 4 & 1 & 21 \\
\hline Finanças & & 1 & & & 1 & 2 & 1 & 1 & 1 & 2 & 2 & 1 & 1 & 2 & 2 & 17 \\
\hline Economia & & & & & & 1 & 1 & & 1 & 1 & 3 & 2 & & 3 & 1 & 13 \\
\hline Estudos organizacionais & & & & & & 1 & & 2 & 1 & & 2 & 2 & 1 & 1 & 3 & 13 \\
\hline Governança corporativa & & & 1 & & 1 & 1 & 1 & 2 & 1 & 3 & 1 & & 2 & & & 13 \\
\hline Mercado de capitais & & & & 1 & 2 & & 2 & 2 & & 1 & & & 1 & 1 & 2 & 12 \\
\hline Gestão pública & & 1 & 1 & & 1 & & 1 & 1 & 1 & 1 & & & & 2 & 2 & 11 \\
\hline Processo decisório & & & & 1 & & & 2 & & 1 & 1 & 2 & 2 & 1 & 1 & & 11 \\
\hline Cultura organizacional & & & & & 1 & 2 & & & & & 2 & 1 & 1 & 1 & 1 & 9 \\
\hline Investimento & & 2 & & 1 & & 1 & 1 & & 1 & & & & 1 & 1 & 1 & 9 \\
\hline Risco & & 2 & & & & 2 & 1 & & 1 & & 1 & 1 & & & 1 & 9 \\
\hline 6 Temas publicados 8 vezes & & & & & & & & & & & & & & & & 48 \\
\hline 4 Temas publicados 7 vezes & & & & & & & & & & & & & & & & 28 \\
\hline 2 Temas publicados 6 vezes & & & & & & & & & & & & & & & & 12 \\
\hline 5 Temas publicados 5 vezes & & & & & & & & & & & & & & & & 25 \\
\hline 3 Temas publicados 4 vezes & & & & & & & & & & & & & & & & 12 \\
\hline 5 Temas publicados 3 vezes & & & & & & & & & & & & & & & & 15 \\
\hline 10 Temas publicados 2 vezes & & & & & & & & & & & & & & & & 20 \\
\hline 33 Temas publicados 1 vez & & & & & & & & & & & & & & & & 33 \\
\hline Total & & & & & & & & & & & & & & & & 364 \\
\hline
\end{tabular}

Fonte: os autores.

O tema Estratégia Organizacional ficou em destaque ao ser colocado em evidência por um número elevado de teorias, o que mostra seu valor no contexto científico nas revistas analisadas. Logo em seguida vem o assunto marketing publicado em 21 estudos. Finanças vem em seguida com 17 publicações, por sua importância nos campos da Gestão, Contabilidade, Economia e Finanças. Os termos Economia, 
Estudos Organizacionais e Governança Corporativa apareceram todos com 13 publicações, e isso é explicado por suas relevâncias diretas na Teoria Institucional e na Teoria de Agência no contexto acadêmico e empresarial. Mercado de Capitais fica em realce em 12 artigos, e, por se tratar de um assunto horizontal, sobretudo no que se refere à Administração, Contabilidade, Economia e Finanças, explica-se tal fato. Os temas Gestão Pública e Processo Decisório também aparecem com suas respectivas relevâncias neste trabalho, com 11 publicações cada um, sendo tal fato em decorrência de suas devidas importâncias no contexto público e empresarial, pois o processo decisório permeia diversas áreas, como a pública e a privada. E, por fim, os assuntos Cultura Organizacional, Investimento e Risco também são destacados com nove publicações cada um.

O que essas informações mostram e contribuem é que as teorias, tanto aquelas enfatizadas neste trabalho quanto aquelas que não foram vistas em destaque são preponderantes para a disseminação e a difusão do conhecimento científico, mediante surgimento, maturidade, emergência e legitimidade de vários temas que englobam as áreas em estudo nesta pesquisa.

Na Figura 1 se visualiza a primeira rede two-mode deste trabalho, que expõe as Teorias em destaque e os periódicos relacionados a elas. O propósito dessa rede é evidenciar uma forma diferente de expor dados e de gerar informações e contribuições, agregando valor a este trabalho.

As Teorias Institucional, das Restrições, da Agência e dos Jogos ficaram em foco nesta seção, ao serem as que mais foram publicadas, em uma maior quantidade de revistas analisadas neste estudo, conseguindo, assim, uma centralidade de grau na rede two-mode. Outro foco neste estudo, por ser uma análise two-mode, é observar os periódicos que mais publicaram artigos que colocavam em evidência as teorias, com isso, notam-se: RAC, RAU, RAM, RGO, BAR, REAd, Recadm, REGE, Rausp e ReA. Dessas 10 revistas, seis são consideradas as mais importantes na disseminação do tema em investigação (Tabela 1). É interessante evidenciar que todas as revistas colocadas em ênfase nesse tópico têm relação direta com a área de Administração, divididas em três periódicos com classificação A2, quatro B1 e três B2, mostrando a diversidade dessas revistas para a difusão e divulgação das teorias que são alicerces de diversos temas. 
Figura 1 - Rede two-mode entre as Teorias em destaque e os periódicos relacionados a elas

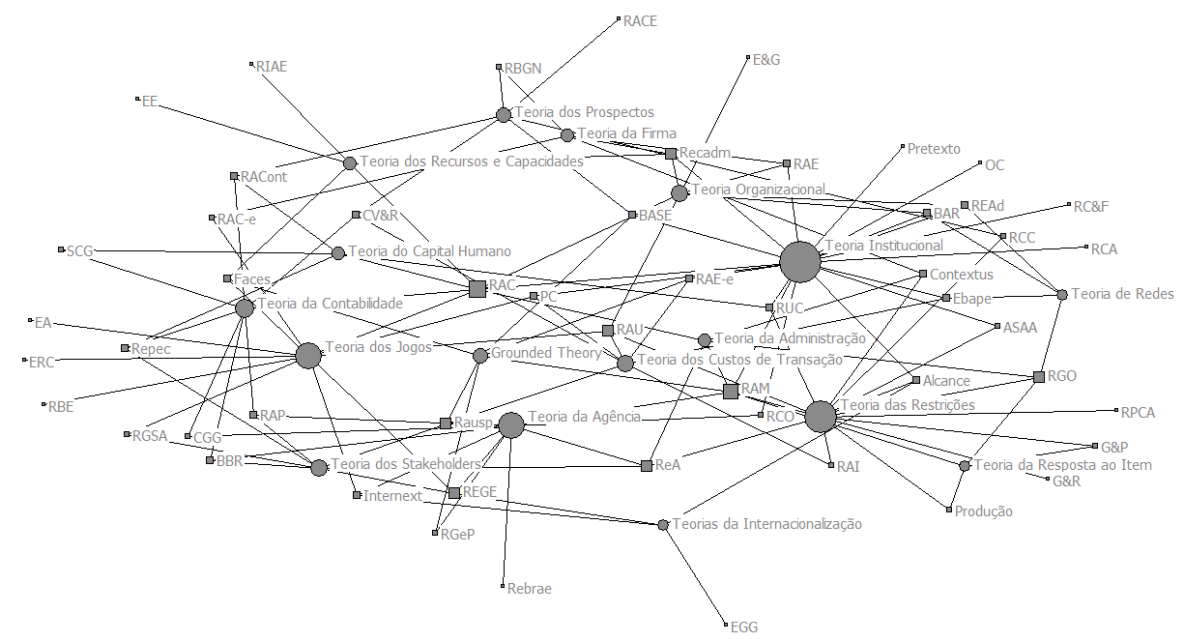

Fonte: os autores.

Os achados desta seção contribuem para melhor entendimento e compreensão da importância dos periódicos para a manifestação das teorias das áreas em investigação, cooperando para o crescimento da produção científica e para a maturidade e legitimidade de assuntos que são primordiais ao esclarecimento de pontos e práticas organizacionais, contábeis, econômicas, financeiras, entre outras, no contexto empresarial e, sobretudo, no panorama acadêmico nacional.

A Figura 2 versa a segunda rede two-mode deste trabalho, colocando em confronto os "atores", teorias em destaque (Tabela 2) e temas relacionados por essas teorias. Verifica-se que Teoria Institucional, Teoria das Restrições, Teoria da Agência, Teoria dos Custos de Transação, Teoria da Contabilidade, Teoria Organizacional e Teoria dos Jogos ficaram em evidência, por abarcarem uma quantidade satisfatória de temas identificados neste estudo. De maneira geral, esse resultado mostra a relevância não apenas dessas teorias que ficaram em destaque nesta seção, mas, também, de todas que foram identificadas neste estudo para a difusão de temas que são preponderantes para a criação de valor e difusão do conhecimento acadêmico, especialmente, nas áreas objeto de estudo desta pesquisa. Informações como essas proporcionam e contribuem para estabelecer nortes e focos de estudos aos acadêmicos já atuantes nos 
campos do saber deste trabalho e/ou aos pesquisadores que desejam se estabelecer cooperando para a otimização do saber científico no contexto nacional.

Observa-se, também, que alguns assuntos foram creditados a teorias que ficaram em relevo neste estudo (vide Tabela 2), como, por exemplo, a estratégia organizacional, que se relacionou com as Teorias Institucional, da Agência, dos Jogos, de Redes, dos Stakeholders, dos Recursos e Capacidades e da Administração. O tema processo decisório também se vinculou com algumas teorias: Teoria das Restrições, Teoria Organizacional, Teoria dos Jogos e Teoria dos Prospectos.

Figura 2 - Rede two-mode entre as Teorias em destaque e os temas relacionados a elas

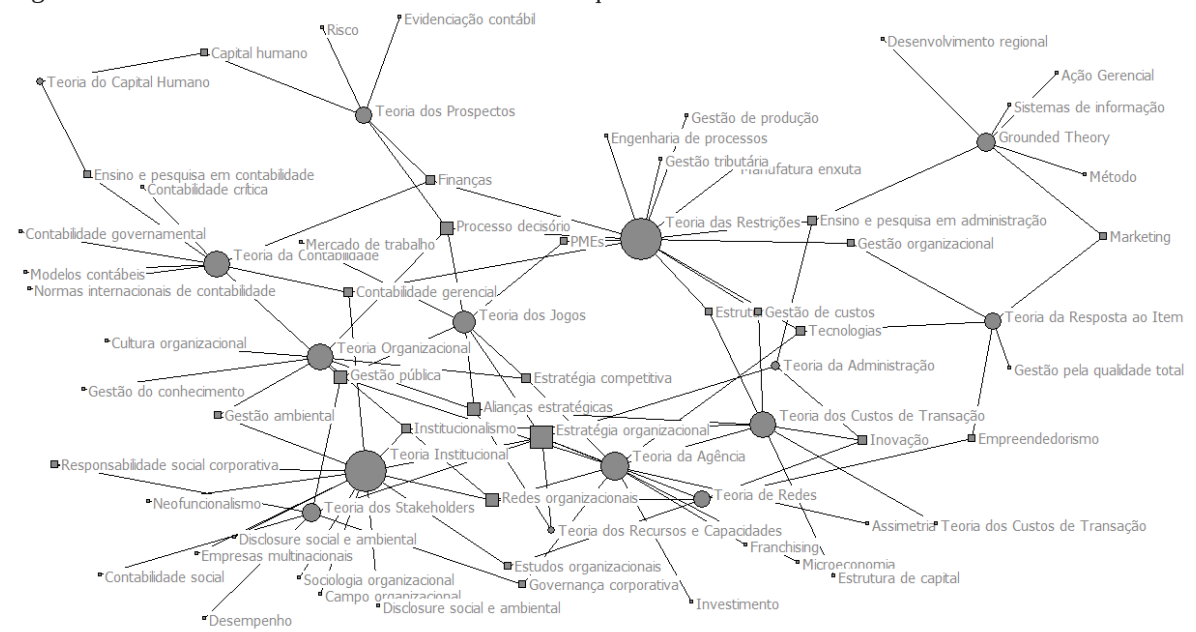

Fonte: os autores.

A gestão pública se conectou com as Teorias da Agência, da Contabilidade, dos Jogos, dos Stakeholders; Alianças estratégicas, com a Teoria Organizacional, a Teoria dos Jogos, a Teoria dos Custos de Transação, a Teoria dos Recursos e Capacidades. Em suma, nesse panorama, versa-se que os próprios assuntos podem ser explicados e embasados por teorias, em especial, aquelas que ficaram em realce neste estudo, proporcionando, com isso, um maior entendimento e compreensão de como esses assuntos estão e são importantes no instante em que permeiam de maneira respectiva o saber científico no cenário da produção acadêmica no Brasil.

Na Figura 3 apresenta-se a terceira rede two-mode desta pesquisa, agora conectando os temas em destaque (Tabela 3 ) e as teorias relacionadas a estes. 
Figura 3 - Rede two-mode entre os temas em destaque e as Teorias relacionadas a eles

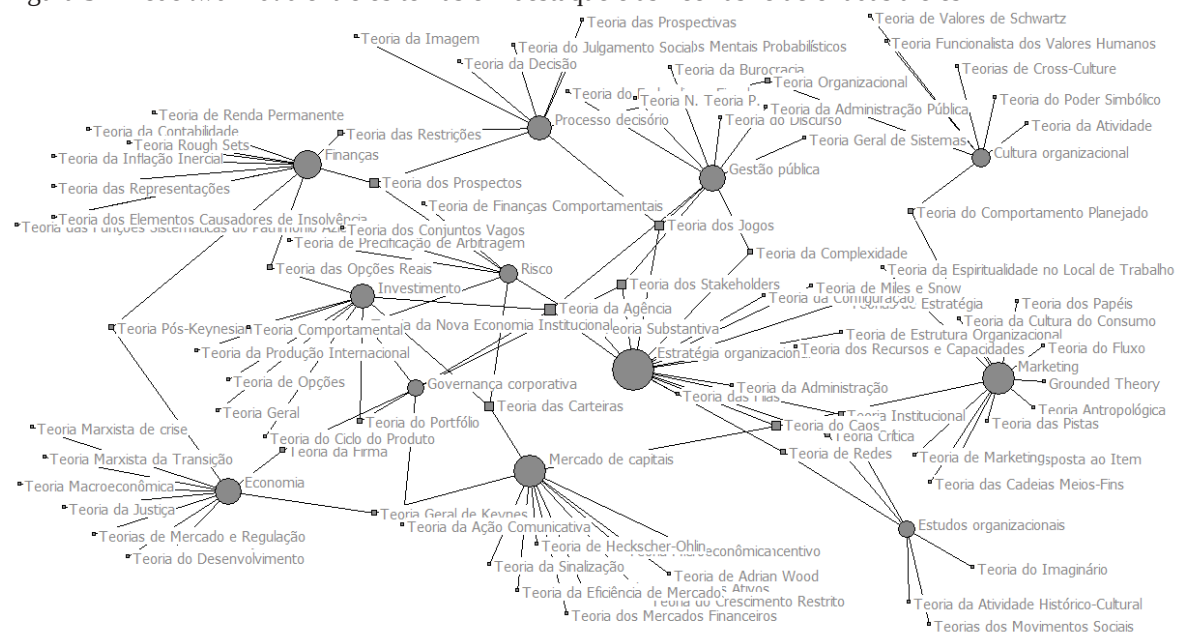

Fonte: os autores.

Nesse cenário, colocam-se em evidência os temas Estratégia Organizacional, Mercado de Capitais, Marketing, Finanças, Processo Decisório, Gestão Pública, Investimento, Economia, Risco, Cultura Organizacional, Governança Corporativa e Estudos Organizacionais. Estes centram-se em algumas teorias, em especial os primeiros, pois obtiveram um maior degree, para alicerçar e robustecer seus pilares teóricos nos artigos investigados neste trabalho. É interessante notar que dos 12 temas em evidência nesta seção, todos estão colocados em realce na Tabela 3, constatando-se, com isso, que estes não somente foram os mais publicados neste artigo, mas também os que mais recorreram nas teorias para robustecer seus respectivos alicerces teóricos.

Os achados contemplados aqui contribuem para se entender que os temas, sobretudo os enfatizados neste estudo, necessitam ser robustecidos por teorias, em especial aquelas que se adaptam às necessidades e cenários dos estudos científicos, ajudando, com isso, a compreender seus respectivos status na produção científica nacional, agregando valor e colaborando para a difusão, a socialização e o alargamento teórico e para o saber científico no Brasil.

\section{CONSIDERAÇÕES FINAIS}

De maneira geral, este trabalho suscitou dados e informações que ainda não tinham sido publicados e/ou divulgados em nenhum outro estudo da academia, e, nesse contexto, este estudo se fez importante, contemplando contribuições atuais e 
essenciais para o fortalecimento da Ciência, no que se refere às teorias por ela utilizadas. Trabalhos como este, que destacou a produção científica de diversas teorias, são necessários para melhor entendimento e compreensão de acadêmicos já atuantes na área e/ou autores que ainda buscam um norte para estudo.

Os achados expostos aqui apresentam diferentes ângulos do saber científico, nos valores que as teorias exercem no balizamento teórico de estudos, acumulando um apanhado de informações úteis para melhor compreensão de temas, que, de acordo com seus status, podem estar permeando divergentes pontos na literatura acadêmica nacional. Contudo, é necessário dizer que, independente disso, as teorias, com seus respectivos vastos arcabouços teóricos, robustecem e proporcionam legitimidade alargada a essas temáticas, proporcionando e contribuindo para difusão, publicação e socialização do conhecimento como um todo dentro do campo que está sendo investigado, que neste estudo é a Administração, Contabilidade e Turismo.

Conhecer as teorias que estão sendo estudadas, desde as embrionárias até as legitimadas nas literaturas científicas nacional e internacional, é importante, pois manifesta informações interessantes e inerentes a tais teorias, propiciando seus respectivos melhores entendimentos no âmbito do cenário acadêmico, impactando e contribuindo, também, para difundir e disseminar os campos do conhecimento da Administração, Contabilidade e afins, influenciando para observar os temas que são relacionados a essas teorias e áreas do saber e, com isso, melhor compreendê-los, colaborando para o surgimento de novas pesquisas, projetos, dissertações, teses, artigos de congressos e periódicos, proporcionando um fomento de estudos em áreas do conhecimento diversas, que necessitam ter teorias que as embasem, surgindo/criando-se alternativas e opções de melhor compreendê-las, propagá-las, difundi-las e socializá-las, como neste estudo se buscou, por meio de seus achados, resultados, discussões, contribuições e conclusões, fazê-lo de maneira mais transparente e coerente possível.

Diante do exposto, neste trabalho concluiu-se de maneira macro, com um dilatado número de dados e informações, substanciados em diferentes nuances da produção acadêmica, a importância das teorias para a propagação do saber científico, criando-se, assim, a possiblidade de melhor entendimento e compreensão dessas teorias para a academia. Este estudo também presta um favor à academia, no instante em que possibilita o surgimento de uma agenda de pesquisa ainda nova no contexto acadêmico nacional, criando a possiblidade de fomentá-la em estudos futuros.

A limitação deste estudo está no panorama da quantidade de anos investigada. Diante disso, esboça-se e sugere-se fomentar essa temporalidade, a fim de, se for o caso, gerar novos dados e informações. Outra limitação foi a análise dos periódicos 
B2 a A2, sendo sugerido, com isso, otimizar, agregando os demais extratos da Qualis Capes, ou seja, B3 a B5. Diante disso, aconselha-se, também, trabalhar um estudo similar a este, não usando apenas revistas nacionais, mas periódicos internacionais com bons fatores de impacto. Outra proposta é aperfeiçoar as técnicas de análise bibliométrica e sociométrica.

\section{REFERÊNCIAS}

AMBONI, N.; CAMINHA, D. O.; ANDRADE, R. O. B. de. Produção acadêmica em Teoria Neo-Institucional no Brasil: 1990 a 2010. Revista Gestão e Planejamento, Salvador, v. 13, n. 2, p. 212-231, maio/ago. 2012.

ANDRADE, J. C. S. Formação de estratégias socioambientais corporativas: os jogos Aracruz Celulose-partes interessadas. Revista de Administração Contemporânea, Curitiba, v. 6, n. 2, p. 75-97, maio/ago. 2002.

ANJOS, C. E. L. dos et al. Produção científica na área de perícia contábil: um estudo bibliométrico em periódicos nacionais. Revista de Contabilidade da UFBA, v. 9, n. 3, p. 48-63, 2015.

ARRUDA, A. G. et al. Teoria dos Custos de Transação (TCT): análises bibliométrica e sociométrica nos Enanpads de 1997 a 2010. Revista de Administração da UNIMEP, Piracicaba, v. 11, n. 2, p. 174-199, maio/ago. 2013.

BARBOSA NETO, J. E.; COLAUTO, R. D. Teoria Institucional: estudo bibliométrico em anais de congressos e periódicos científicos. ConTexto, Porto Alegre, v. 10, n. 18, p. 63-74, jul./dez. 2010.

BASSO, L. F. C.; PACE, E. S. U. Uma análise crítica da direção da causalidade no balanced scorecard. RAE eletrônica, v. 2, n. 1, p. 1-21, 2003.

BATISTA, P. C. de S. et al. As relações contratuais das indústrias criativas: o caso dos quadrinhos no Ceará. CADERNOS EBAPE. BR, Rio de Janeiro, v. 9, n. 2, p. 377-393, 2011.

BERTERO, C. O. Influências sociológicas em teoria organizacional. Revista de Administração de Empresas, v. 15, n. 6, p. 27-37, 1975. 
BEUREN, I. M.; SOUZA, J. C. de. Em busca de um delineamento de proposta para classificação dos periódicos internacionais de contabilidade para o Qualis CAPES. Revista Contabilidade \& Finanças, São Paulo, v. 19, n. 46, p. 44-58, jan./abr. 2008.

BORTOLOTTI, S. L. V. et al. Avaliação do nível de satisfação de alunos de uma instituição de ensino superior: uma aplicação da Teoria da Resposta ao Item. Gestão \& Produção, São Carlos, v. 19, n. 2, p. 287-302, 2012.

CALIXTO, L. A divulgação de relatórios de sustentabilidade na América Latina: um estudo comparativo. Revista de Administração da USP, São Paulo, v. 48, n. 4, p. 828-842, out./dez. 2013.

CAPPELLOZZA, A.; SANCHEZ, O. P. Análise de decisões sobre uso de tecnologia: um estudo no setor de telefonia móvel fundamentado nos axiomas da economia comportamental. Revista de Administração Contemporânea, Curitiba, v. 15, n. 6, p. 1078-1099, nov./dez. 2011.

CARDOSO, R. L. et al. Pesquisa científica em contabilidade entre 1990 e 2003. Revista de Administração de Empresas, São Paulo, v. 45, n. 2, p. 34-45, abr./jun. 2005.

CHIAPPIN, J. R. N. Huntington's paradigm and political realism. Lua Nova: Revista de Cultura e Política, v. 34, n. 34, p. 37-53, 1994.

COLAUTO, R. D.; ALMEIDA, V. E. de. Teoria institucional associada à contabilidade gerencial: estudo bibliométrico 2009-2012. Revista Ciências Sociais em Perspectiva, Cascavel, v. 12, n. 22, p. 1-21, jan./jun. 2013.

CRUZ, A. P. C. da et al. Condicionantes da especificidade de ativos das maiores empresas no Brasil sob a ótica da Teoria Econômica dos Custos de Transação. Revista Contabilidade Vista \& Revista, Belo Horizonte, v. 22, n. 2, p. 155-180, abr./ jun. 2011a.

CRUZ, A. P. C. da et al. Perfil das redes de cooperação científica: congresso USP de controladoria e contabilidade - 2001 a 2009. Revista Contabilidade \& Finanças, São Paulo, v. 22, n. 55, p. 64-87, jan./abr. 2011 b. 
CRUZ, C. et al. Teoria das Restrições: um estudo bibliométrico da produção científica Custos. In: ABCustos, 5., São Leopoldo, 2010. Anais Eletrônicos... São Leopoldo: ABCustos, 2010. Disponível em: <http://www.unisinos.br/abcustos/>. Acesso em: 13 fev. 2015.

CUNHA, J. V. A. da; CORNACHIONE JÚNIOR, E. B.; MARTINS, G. de A. Doutores em Ciências Contábeis: análise sob a óptica da Teoria do Capital Humano.

Revista de Administração Contemporânea, Curitiba, v. 14, n. 3, p. 532-557, maio/ jun. 2010.

DJALÓ, A. B.; PROCOPIUCK, M. Teoria e prática na construção do conhecimento em administração. Revista Eletrônica de Ciência Administrativa, Campo Largo, v. 9, n. 1, p. 90-103, jan./jun. 2010.

FASSIN, Y. A dynamic perspective in Freeman's stakeholder model. Journal of Business Ethics, EUA, v. 96, n. 1, p. 39-49, ago. 2010.

FASSIN, Y. Imperfections and shortcomings of the stakeholder model's graphical representation. Journal of Business Ethics, EUA, v. 80, n. 4, p. 879-888, jul. 2008.

FERREIRA, M. P.; PINTO, C. F.; SERRA, F. R. The transaction costs theory in international business research: a bibliometric study over three decades. Scientometrics, Budapest, v. 97, n. 2, p. 1-26, nov. 2013.

FREEMAN, R. E.; REED, D. L. Stockholders and stakeholders: a new perspective on corporate governance. California Management Review, EUA, v. 25, n. 3, p. 88-106, 1983.

FUJI, A. H.; SLOMSKI, V. Subjetivismo responsável: necessidade ou ousadia no estudo da contabilidade. Revista Contabilidade \& Finanças, São Paulo, v. 14, n. 33, p. 33-44, set./dez. 2003.

GIACON, E.; MESQUITA, M. A. de. Levantamento das práticas de programação detalhada da produção: um survey na indústria paulista. Gestão \& Produção, São Carlos, v. 18, n. 3, p. 487-498, 2011.

GOMES, E. do C. O.; SCARPIN, J. E. Estudo bibliométrico acerca das transferências intergovernamentais publicadas no período de 2001 a 2008. Revista de Administração e Contabilidade da Unisinos, Porto Alegre, v. 9, n. 2, p. 189-203, abr./jun. 2012. 
GONDIM, S. M. G. et al. Da descrição do caso à construção da teoria ou da teoria à exemplificação do caso? Uma das encruzilhadas da produção do conhecimento em administração e áreas afins. Organizações \& Sociedade, Salvador, v. 12, n. 35, p. 47-68, out./dez. 2005.

GUARIDO FILHO, E. R.; MACHADO-DA-SILVA, C. L.; GONÇALVES, S. A. Organizational institutionalism in the academic field in Brazil: social dynamics and networks. Revista de Administração Contemporânea, Curitiba, v. 14, p. 149-172, set. 2010. Edição Especial.

GUBIANI, C. A.; LAVARDA, C. E. F. Perfil da produção bibliográfica sobre finanças comportamentais e Teoria do Prospecto. Revista de Administração, Contabilidade e Economia, Joaçaba, v. 10, n. 2, p. 163-184, jul./dez. 2011.

GUERREIRO, R.; CORNACHIONE JÚNIOR, E. B.; SOUTES, D. O. Empresas que se destacam pela qualidade das informações a seus usuários externos também se destacam pela utilização de artefatos modernos de contabilidade gerencial? Revista Contabilidade \& Finanças, São Paulo, v. 22, n. 55, p. 88-113, jan./abr. 2011.

HAYASHI, M. C. P. I. et al. Obra do Padre Antônio Vieira na agenda das pesquisas acadêmicas no Brasil. ETD: Educaçao Temática Digital, v. 14, n. 1, p. 96-120, 2012.

JABBOUR, C. J. C.; SANTOS, F. C. A.; BARBIERI, J. C. Gestão ambiental empresarial: um levantamento da produção científica brasileira divulgada em periódicos da área de administração entre 1996 e 2005. Revista de Administração Contemporânea, Curitiba, v. 12, n. 3, p. 689-715, jul./set. 2008.

JENSEN, M. C.; MECKLING, W. H. Theory of the firm: managerial behavior agency, costs and ownership structure. Journal of Financial Economics, Amsterdam, v. 3, i. 4, p. 305-360, Oct. 1976.

KIMURA, H.; BASSO, L. F. C.; MARTIN, D. M. L. Redes sociais e o marketing de inovações. Revista de Administração Mackenzie, São Paulo, v. 9, n. 1, p. 157-181, 2008.

KOBASHI, N. Y.; SANTOS, R. N. M. dos. Arqueologia do trabalho imaterial: uma aplicação bibliométrica à análise de dissertações e teses. Encontros Bibli: Revista Eletrônica de Biblioteconomia e Ciência da Informação, v. 13, n. 1, p. 106-115, 2008. 
KOBASHI, N. Y.; SANTOS, R. N. M. dos. Institucionalização da pesquisa científica no Brasil: cartografia temática e de redes sociais por meio de técnicas bibliométricas. TransInformação, v. 18, n. 1, p. 27-36, 2006.

KOVACS, E. P.; MORAES, W. F. A. de; OLIVEIRA, B. R. B. de. Características da localização no processo de internacionalização de empresas. Revista de Administração de Empresas, São Paulo, v. 51, n. 4, p. 320-335, jul./ago. 2011.

LACERDA, D. P. et al. Design Science Research: método de pesquisa para a engenharia de produção. Gestão \& Produção, São Carlos, v. 20, n. 4, p. 741-761, nov. 2013.

LEITE FILHO, G. A. Padrões de produtividade de autores em periódicos e congressos na área de contabilidade no Brasil: um estudo bibliométrico. Revista de Administração Contemporânea, Curitiba, v. 12, n. 2, p. 533-554, abr./jun. 2008.

LOPES, F. D.; BALDI, M. Redes como perspectiva de análise e como estrutura de governança: uma análise das diferentes contribuições. Revista de Administração Pública, Rio de Janeiro, v. 43, n. 5, p. 1007-1035, set./out. 2009.

LORÊTO, M. S. da S.; PACHECO, F. L. A inserção da lógica de mercado no campo cultural: a relação entre as instituições bancárias e a cultura em Recife. Cadernos EBAPE.BR, Rio de Janeiro, v. 5, n. 4, p. 1-14, dez. 2007.

MACHADO JÚNIOR, C. A influência de pesquisadores do stricto sensu em administração na legitimação do conhecimento em sustentabilidade ambiental. 2012. 230 p. Tese (Doutorado em Administração)-Universidade Nove de Julho, São Paulo, 2012.

MACHADO JÚNIOR, C. et al. Análise de viabilidade de utilizar as leis da bibliometria em diferentes bases de pesquisa. In: ASSOCIAÇÃO NACIONAL DE PÓS-GRADUAÇÃO E PESQUISA EM ADMINISTRAÇÃO, 38., Rio de Janeiro, 2014. Anais Eletrônicos... Rio de Janeiro: ANPAD, 2014. Disponível em: <http:// www.anpad.org.br/>. Acesso em: 13 fev. 2015.

MACHADO JÚNIOR, C.; SOUZA, M. T. S. de; PARISOTTO, I. R. dos S. Institucionalização do conhecimento em sustentabilidade ambiental pelos programas de pós-graduação stricto sensu em administração. Revista de Administração Contemporânea, Curitiba, v. 18, n. 6, p. 854-873, nov./dez. 2014. 
MACHADO NETO, A. J.; ALMEIDA, F. C. de. A internacionalização da indústria calçadista francana. Revista de Administração Mackenzie, São Paulo, v. 9, n. 8, p. 88-111, nov./dez. 2008.

MARTINS, D. de L. C. da C.; SOUZA, J. P. de. Atributos da transação e mensuração e sua influência nas relações entre cooperados e cooperativas em sistemas agroindustriais suinícolas. Revista de Administração Mackenzie, São Paulo, v. 15, n. 3, p. 69-100, maio/jun. 2014.

MEDEIROS, J. M. G. de; VITORIANO, M. A. V. A evolução da bibliometria e sua interdisciplinaridade na produção científica brasileira. Revista Digital de Biblioteconomia e Ciência da Informação, v. 13, n. 3, p. 491-503, 2015.

MENEGHETTI, F. K. O que é um ensaio-teórico? Revista de Administração Contemporânea, Curitiba, v. 15, n. 2, p. 320-332, mar./abr. 2011.

MISOCZKY, M. C. A. Implicações do uso das formulações sobre campo de poder e ação de bourdieu nos estudos organizacionais. Revista de Administração Contemporânea, Curitiba, v. 7, p. 9-30, 2003. Edição Especial.

MORETTI, S. L. do A.; CAMPANARIO, M. de A. A produção intelectual brasileira em responsabilidade social empresarial - RSE sob a ótica da bibliometria. Revista de Administração Contemporânea, Curitiba, v. 13, p. 68-86, jun. 2009. Edição Especial.

NEVES, M. F.; CONEJERO, M. A. Uma contribuição empírica para geração de métodos de planejamento e gestão. Revista de Administração da USP, São Paulo, v. 47, n. 4, p. 699-714, out./dez. 2012.

OLIVEIRA, M. C. Análise dos periódicos brasileiros de contabilidade. Revista Contabilidade \& Finanças, São Paulo, v. 13, n. 29, p. 68-86, maio/ago. 2002.

PELEIAS, I. R. et al. Produção científica sobre controle interno e gestão de riscos no Enanpad e congresso USP: análise bibliométrica no período 2001-2011. Revista Universo Contábil, Blumenau, v. 9, n. 4, p. 29-49, out./dez. 2013.

PEREIRA, F. A. de M. A evolução da Teoria Institucional nos estudos organizacionais: um campo de pesquisa a ser explorado. Organizações em Contexto, São Bernardo do Campo, v. 8, n. 16, p. 275-295, jul./dez. 2012. 
PLANTULLO, V. L. Um pouco além do just-in-time: uma abordagem à Teoria das Restrições. Revista de Administração de Empresas, São Paulo, v. 34, n. 5, p. 3239, set./out. 1994.

RIBEIRO, H. C. M. Características da produção veiculada na Revista de Educação e Pesquisa em Contabilidade no período de 2007 a 2012. Revista de Educação e Pesquisa em Contabilidade, Brasília, DF, v. 7, n. 4, p. 424-443, out./dez. 2013a.

RIBEIRO, H. C. M.; COSTA, B. K.; FERREIRA, M. A. S. P. V. Produção acadêmica dos temas estratégia e governança corporativa. Revista de Administração FACES, Belo Horizonte, v. 13, n. 3, p. 27-46, jul./set. 2014.

RIBEIRO, H. C. M. et al. Visão Baseada em Recursos: uma análise bibliométrica dos últimos 11 anos. Revista de Ciências da Administração, Florianópolis, v. 14, n. 34, p. 39-59, dez. 2012.

RIBEIRO, H. C. M. Revista Contemporânea de Contabilidade: uma análise do perfil da produção acadêmica durante o período de 2004 a 2012. Revista Contemporânea em Contabilidade, Florianópolis, v. 10, n. 20, p. 3-27, maio/ago. 2013 b.

ROCHA, I. et al. Análise da produção científica sobre Teoria da Agência e assimetria da informação. Revista de Gestão da USP, São Paulo, v. 19, n. 2, p. 327-340, abr./ jun. 2012.

RODRIGUES, A. L.; MALO, M. C. Estruturas de governança e empreendedorismo coletivo: o caso dos doutores da alegria. Revista de Administração Contemporânea, Curitiba, v. 10, n. 3, p. 29-50, jul./set. 2006.

RODRIGUES, S. B.; CARRIERI, A. de P. A tradição anglo-saxônica nos estudos organizacionais brasileiros. Revista de Administração Contemporânea, Curitiba, v. 5, p. 81-102, 2001. Edição Especial.

ROSSONI, L.; GUARIDO FILHO, E. R. Cooperação entre programas de pós-graduação em administração no Brasil: evidências estruturais em quatro áreas temáticas. Revista de Administração Contemporânea, Curitiba, v. 13, n. 3, p. 366-390, jul./ ago. 2009.

ROSSONI, L.; HOCAYEN-DA-SILVA, A. J. Cooperação entre pesquisadores da área de administração da informação: evidências estruturais de fragmentação das relações no campo científico. Revista de Administração da USP, v. 43, n. 2, p. 138-151, 2008. 
ROSSONI, L.; HOCAYEN-DA-SILVA, A. J.; FERREIRA JÚNIOR, I. Aspectos estruturais da cooperação entre pesquisadores no campo de administração pública e gestão social: análise das redes entre instituições no Brasil. Revista de Administração Pública, Rio de Janeiro, v. 42, n. 6, p. 1041-1067, nov./dez. 2008.

SANTOS, R. dos. “Jogos de empresas” aplicados ao processo de ensino e aprendizagem de contabilidade. Revista Contabilidade \& Finanças, São Paulo, v. 14, n. 31, p. 78-95, jan./abr. 2003.

SARTORI, S. et al. Mapeamento do estado da arte do tema sustentabilidade ambiental direcionado para a tecnologia de informação. Transinformação, Campinas, v. 26, n. 1, p. 77-89, jan./abr. 2014.

SILVA, M. R. da; HAYASHI, C. R. M.; HAYASHI, M. C. P. I. Análise bibliométrica e cientométrica: desafios para especialistas que atuam no campo. InCID: R. Ci. Inf. e Doc., Ribeirão Preto, v. 2, n. 1, p. 110-129, jan./jun. 2011.

SILVA, S. C. da; ZUCCOLOTTO, R. Propriedades dos estudos de Teoria da Contabilidade em um periódico científico brasileiro. Enfoque: Reflexão Contábil, Maringá, v. 33, n. 2, p. 35-53, maio/ago. 2014.

SOUZA, F. J. V. de et al. Perfil dos artigos sobre Teoria dos Ajustamentos Contábeis do Lucro: um estudo nos periódicos de contabilidade com estrato Capes no triênio 2010-2012. Revista de Administração e Contabilidade, Feira de Santana, v. 5, n. 1, p. 22-37, set./dez. 2013.

SOUZA, M. T. S. de; RIBEIRO, H. C. M. Sustentabilidade ambiental: uma meta-análise da produção brasileira em periódicos de administração. Revista de Administração Contemporânea, Curitiba, v. 17, n. 3, p. 368-396, maio/jun. 2013.

VEDRES, B.; STARK, D. Dobras estruturais: ruptura generativa em grupos sobrepostos. Revista de Administração de Empresas, São Paulo, v. 50, n. 2, p. 215-240, abr./jun. 2010.

VITORINO FILHO, V. A. et al. A produção científica brasileira em cooperação empresarial. Revista de Administração e Inovação, São Paulo, v. 9, n. 3, p. 175-194, jul./set. 2012. 
WALTER, S. A.; BACH, T. M. Inserção de pesquisadores entrantes na área de estratégia: análise das relações de autoria e temas estudados no período de 1997-2010. Revista Eletrônica de Administração, Porto Alegre, v. 19, n. 1, p. 165-191, jan./ abr. 2013.

WHETTEN, D. A. O que constitui uma contribuição teórica? Revista de Administração de Empresas, São Paulo, v. 43, n. 3, p. 69-73, jul./set. 2003.

Como citar este artigo:

\section{ABNT}

RIBEIRO, Henrique, Cesar; Melo; SANTOS, Marianne, Corrêa dos. Produção acadêmica das teorias enfatizadas nos estudos divulgados nos periódicos nacionais. RACE, Revista de Administração, Contabilidade e Economia, Joaçaba: Ed. Unoesc, v. 15, n. 2, p. 649-684, maio/ago. 2016. Disponível em: <http://editora.unoesc. edu.br/index.php/race>. Acesso em: dia/mês/ano.

\section{APA}

Ribeiro, H. C. M., \& Corrêa dos Santos, M. C. (2016) Produção acadêmica das teorias enfatizadas nos estudos divulgados nos periódicos nacionais RACE, Revista de Administração, Contabilidade e Economia, 15(2), 649-684. Recuperado de http:// editora.unoesc.edu.br/index.php/race 